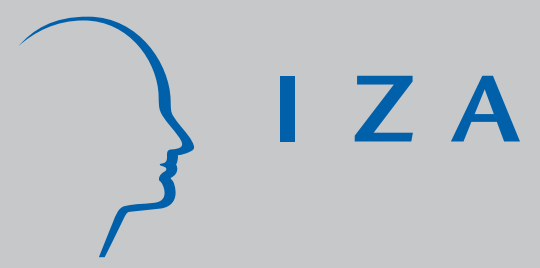

IZA DP No. 412

Government Debt as Insurance against Macroeconomic Risk

Martin Barbie

Marcus Hagedorn

Ashok Kaul

December 2001 


\title{
Government Debt as Insurance against Macroeconomic Risk
}

\author{
Martin Barbie \\ Department of Economics, University of Bonn \\ Marcus Hagedorn \\ IZA, Bonn and University of Bonn \\ Ashok Kaul \\ $I Z A$, Bonn and University of Bonn
Discussion Paper No. 412
December 2001

\author{
IZA \\ P.O. Box 7240 \\ D-53072 Bonn \\ Germany \\ Tel.: +49-228-3894-0 \\ Fax: +49-228-3894-210 \\ Email: iza@iza.org
}

This Discussion Paper is issued within the framework of IZA's research area General Labor Economics. Any opinions expressed here are those of the author(s) and not those of the institute. Research disseminated by IZA may include views on policy, but the institute itself takes no institutional policy positions.

The Institute for the Study of Labor (IZA) in Bonn is a local and virtual international research center and a place of communication between science, politics and business. IZA is an independent, nonprofit limited liability company (Gesellschaft mit beschränkter Haftung) supported by the Deutsche Post AG. The center is associated with the University of Bonn and offers a stimulating research environment through its research networks, research support, and visitors and doctoral programs. IZA engages in (i) original and internationally competitive research in all fields of labor economics, (ii) development of policy concepts, and (iii) dissemination of research results and concepts to the interested public. The current research program deals with (1) mobility and flexibility of labor, (2) internationalization of labor markets, (3) the welfare state and labor markets, (4) labor markets in transition countries, (5) the future of labor, (6) evaluation of labor market policies and projects and (7) general labor economics.

IZA Discussion Papers often represent preliminary work and are circulated to encourage discussion. Citation of such a paper should account for its provisional character. 


\section{ABSTRACT \\ Government Debt as Insurance against Macroeconomic Risk}

Is there a role for debt beyond curing overaccumulation of capital? Does dynamic efficiency and the infeasibility of debt Ponzi schemes eliminate any Pareto-improving role for a government in a competitive economy with complete markets? Is there an optimal maturity structure of public debt? Using a stochastic Diamond OLG model, we tackle these questions. We show that government debt can Pareto-improve upon market allocations through a mechanism that resembles a Ponzi scheme. But instead of rolling over safe debt, we can interpret our scheme as one that rolls over an insurance contract generation for generation. This kind of dynamic risk-sharing can provide insurance against macroeconomic risk. Using the widespread welfare concept of interim Pareto optimality, we ensure that all generations voluntarily participate in our insurance scheme. Yet, the scheme cannot be replicated on capital markets. Exploiting information from the term structure of interest rates, we derive testable conditions both for dynamic efficiency and for interim Pareto optimality in terms of interest rates. We provide evidence that real world economies, while being dynamically efficient, are likely not to be interim Pareto optimal. We conclude that there may be a welfareimproving role for a well-designed maturity structure of debt.

JEL Classification: D61, H63, H55, E43

Keywords: Stochastic OLG model, government debt, macroeconomic risk, dynamic efficiency, interim pareto optimality, maturity structure

Marcus Hagedorn

IZA

P.O. Box 7240

D-53072 Bonn

Germany

Tel.: +492283894509

Fax: +492283894510

Email: hagedorn@iza.org

\footnotetext{
* We are indebted to Georg Nöldeke, Heraklis Polemarchakis, Izthak Zilcha and Bert Füssenich for many helpful comments. Furthermore, we would like to thank Don Brown and Gabrielle Demange for helpful discussions.
} 


\section{Introduction}

Public debt issued in bonds is an important policy instrument in modern economies. For example, bonds enable households to transfer resources to the future in order to save for their old age. The government in turn can use debt policy to deal with economic fluctuations. But what is the appropriate amount of debt? And, for a given present value of debt, does the structure of debt matter, i.e, does it for example matter whether debt is held by the public in one-period or two-period bonds? Introducing the overlapping generations model of capital accumulation, Diamond (1965) has shown in a celebrated contribution that government debt can cure overaccumulation of capital by issuing an optimal level of debt. However, the OLG paradigm is silent as a theory of the optimal structure of public debt. ${ }^{1}$ Furthermore, the empirical relevance of a role of debt policy in the Diamond model has been questioned, because real world economies are considered to be dynamically efficient since the influential contribution of Abel, Summers, Mankiw and Zeckhauser (1989) [AMSZ from here on]. Seemingly related, the prevalent opinion in the literature has been that debt Ponzi schemes are not sustainable, in spite of a safe interest rate that has been on average lower than the growth rate of the US economy over the last century. $^{2}$

We reconsider the role of government debt in a stochastic version of the Diamond model. Our contribution is twofold. First, maintaining the important assumption of complete markets, we identify a yet undiscovered insurance role for a well-designed government debt policy which is ruled out neither by dynamic efficiency nor by the infeasibility of debt Ponzi schemes. Second, we show how this role is related to the term structure of interest rates and the design of an optimal maturity structure of public debt.

Our analysis reveals that individuals who have exploited all insurance possibilities on complete insurance markets and are thus only left with aggregate (macroeconomic) risk, can be insured against this risk by an optimal debt policy. This debt policy implicitly provides the individuals with high transfers in economic downturns and low transfers in booms during their old age, smoothing their old age consumption. Thus, we do not consider the well-known potential role of a government in providing missing insurance

\footnotetext{
${ }^{1}$ The literature on optimal fiscal policy, which has been mainly developed within the Arrow-Debreu paradigm, has identified public debt as an instrument through which insurance against fiscal shocks can be provided. Thereby, a well-designed structure of debt can smooth tax distortions across time and states which arise because an exogenously given tax revenue has to be raised [Barro (1979), Lucas and Stokey (1983)]. We are not concerned with the necessity of a government to raise taxes and thus tax distortions are absent in our model.

${ }^{2}$ See Bohn (1995) and Elmendorf and Mankiw (1999), section 4.2.3, for a concise survey of the literature.
} 
markets against the state in which an individual is born [Gordon and Varian (1988), Blanchard and Weil (1992, 2001), Bohn (1998b)].

But how can a debt policy deal with aggregate risk? The key insight is that the dynamic structure of the economy allows the government to implement a chain of uninterrupted intergenerational insurance contracts. Each generation is promised a statecontingent transfer during old age in order to reduce aggregate consumption risk. The promise is kept by ensuring that the next generation voluntarily participates in the intergenerational contract. This is possible by using the standard welfare concept of interim Pareto optimality. This grand contract is rolled over generation for generation. It is important to relate this mechanism to the one underlying debt Ponzi schemes. Instead of rolling over safe debt, our scheme can be interpreted as one that rolls over a dynamic insurance contract generation for generation. We call this kind of dynamic risk-sharing a sophisticated Ponzi scheme.

We provide a complete characterization as well as testable criteria when such a scheme is feasible and welfare-improving. In an abstract form, the necessary information to assess the feasibility of such a contract is given by the various marginal rates of substitution between consumption in the state today and the different states in the future. We succeed in condensing this unobservable information into bond interest rates of different maturity. Furthermore, in order to avoid the counterfactual assumption of state-contingent debt, we show how the deliberate choice of the maturity structure of public debt can endogenously generate state-contingent payoffs necessary to support a welfare improving policy. We formally relate our approach to the literature on dynamic efficiency [Cass (1972), Zilcha (1990), Dechert and Yamamoto (1992)]. Furthermore, motivated by the observation of low bond interest rates over the last century, we precisely disentangle the conceptual difference between dynamic efficiency and debt Ponzi schemes [see Blanchard and Weil $(1992,2001)$ for an important first approach]. We show that under uncertainty, debt Ponzi schemes are not ruled out by dynamic efficiency. However, neither dynamic efficiency nor the infeasibility of debt Ponzi schemes rule out the kind of insurance that is at the heart of our paper. We present evidence that the US economy, while being dynamically efficient, is still likely to offer a welfare-improving role for a well-designed debt policy. Our results rehabilitate the Diamond model of overlapping generations as a model that can identify empirically relevant inefficiencies of competitive equilibria.

As an example of an important field of application of our results consider recent proposals such as the social security administration's plan to invest a portion of the US Social Security Trust Fund in equities. The ongoing discussion is mainly guided 
by arguments contrasting two assets - debt and equity. Our analysis establishes that models considering debt as a single asset neglect an important source of uncertainty. The structure of debt matters for providing individuals today with insurance against macroeconomic risk when they retire. Roughly speaking, our results establish that the Trust Fund payments to a particular generation should be supplemented in economic downturns. The debt due to the supplementary payments should be rolled over similar as in a debt Ponzi scheme, yet in a more sophisticated way. Since the current structure of debt in the Social Security Trust Fund is not deliberately designed in order to provide such an insurance, there is likely to be a welfare-improving role in reconsidering the debt portfolio of the Trust Fund.

The paper is organized as follows. Section 2 describes the stochastic Diamond model. Section 3 develops a new role for debt in the stochastic Diamond model. Section 3.1 gives a complete characterization of interim Pareto optimality in a competitive equilibrium. Section 3.2 derives testable criteria for suboptimality. Section 3.3 considers the full scope of a government in providing insurance against macroeconomic risk. Section 4 considers potentially relevant restrictions on the set of Pareto-improving policies. Section 4.1 focuses on dynamic efficiency, and section 4.2 deals with debt Ponzi schemes. In section 4.3, we discuss in detail the relationship of our approach to the one adopted by AMSZ. Section 5 presents some empirical evidence about dynamic efficiency and in particular about interim Pareto optimality of the US economy. Section 6 concludes.

\section{The Model}

We consider a stochastic version of the Diamond (1965) model. Uncertainty enters the model via shocks to the production technology. Time is discrete, starts at 0 and extends infinitely into the future. There is production and a consumption-saving decision at every point of time.

Production The production technology at time $t$ is described by a function $F: \mathbb{R}_{+}^{2} \times A_{t} \rightarrow$ $\mathbb{R}_{+}$where $F\left(K_{t}, L_{t}, \theta_{t}\right)$ is the output produced at time $t$, given the capital stock $K_{t}$, labor input $L_{t}$ and the current stochastic shock $\theta_{t}$. The perishable good produced by the technology is the only good in the economy and is used for production and consumption. For simplicity, the depreciation rate rate is assumed to be 1 .

More specifically, the production function satisfies:

- $F\left(K_{t}, L_{t}, \theta_{t}\right)$ is homogeneous of degree 1 in $K_{t}, L_{t}$, strictly increasing, strictly concave and twice continuously differentiable in $K_{t}, L_{t}$. Further, $F\left(0, L_{t}, \theta_{t}\right)=F\left(K_{t}, 0, \theta_{t}\right)=$ 
0. It also satisfies the Inada conditions $\lim _{K_{t} \rightarrow 0} F_{K}\left(K_{t}, L_{t}, \theta_{t}\right)=\infty$ and $\lim _{K_{t} \rightarrow \infty} F_{K}\left(K_{t}, L_{t}, \theta_{t}\right)=0$. As usual, define $f\left(k_{t}, \theta_{t}\right)=F\left(\frac{K_{t}}{L_{t}}, 1, \theta_{t}\right)$, the per capita production function. It inherits from $F$ the following properties:

$f^{\prime}=\frac{\partial f}{\partial k}>0, f^{\prime \prime}<0, f^{\prime}\left(0, \theta_{t}\right)=\infty, f^{\prime}\left(\infty, \theta_{t}\right)=0$.

Uncertainty W.l.o.g, for each period in time $t \geq 1$, the set of production shocks, $A_{t}=A$, is assumed to have finite cardinality and $A_{0}$ is assumed to be single valued. ${ }^{3}$ We assume that there is a well-defined system of conditional probabilities $q_{t+1}\left(\theta_{t+1} \mid \sigma\right)$ where $\sigma:=$ $\left(\theta_{0}, \theta_{1}, \theta_{2}, \ldots, \theta_{t}\right)$ and the $q_{t+1}\left(\theta_{t+1} \mid \sigma\right)$ are strictly positive for every $\theta_{t+1} \in A_{t+1}$.

Since the production shocks are the only source of uncertainty in the economy, it is possible to describe the uncertainty by a date-event tree, where $\sigma_{0}=\left\{\theta_{0}\right\}$ is the root and $\sigma=\left(\theta_{0}, \theta_{1}, \theta_{2}, \ldots, \theta_{t}\right)$ is a generic node. If we want to stress the date of a node we write $\sigma_{t}$. The set of nodes at time $t$ is therefore $A_{0} \times A_{1} \times A_{2} \times \ldots \times A_{t}$ and denoted by $\Sigma_{t}$. The date-event tree is denoted by $\Gamma$ and in slight abuse of notation we will identify it with the set of its nodes $\cup_{t \geq 0} \Sigma_{t}$. Every node $\sigma=\left(\theta_{0}, \theta_{1}, \theta_{2}, \ldots, \theta_{t}\right)$ has a unique immediate predecessor, denoted $\sigma_{-1}$, which is equal to $\left(\theta_{0}, \theta_{1}, \theta_{2}, \ldots, \theta_{t-1}\right) . \sigma^{-}$denotes the set of all predecessor nodes of node $\sigma . \sigma^{+}$denotes the set of nodes which are immediate successors of node $\sigma$, i.e. the set of all nodes for which $\sigma$ is the immediate predecessor. A path is a sequence of nodes $\left\{\sigma_{t}\right\}_{t \geq 0}$ such that $\sigma_{t+1} \in \sigma_{t}^{+}$. A generic path will be denoted by $\sigma^{\infty}$ and $\sigma_{t}^{\infty}$ denotes the t-th coordinate of the path $\sigma^{\infty} . t(\sigma)$ denotes the period of time at which event $\sigma \in \Sigma_{t}$ occurs.

Households At each node in the tree one consumer is born who lives for two periods. ${ }^{4}$ Hence agents are distinguished according to date and state of nature in which they are born. Therefore, agents can be identified with the node at which they are born, so that in the rest of the paper the agent born in node $\sigma$ will be called agent $\sigma$ or generation $\sigma$.

Since time starts at 0 we have one initially, i.e. at $t=0$, old agent (born in period -1 so to speak). This agent has preferences which are strictly monotone in the single consumption good in period 0 . His consumption in period 0 is denoted by $c^{o}\left(\sigma_{0}\right)$.

Consider now all other agents. Due to the production shocks they have an uncertain second period of life. The consumption set of agent $\sigma$ is $\mathbb{R}_{+}^{1+S}$, where $S$ is the cardinality of $A$ if the agent is born in period $t$. His von Neumann-Morgenstern preferences are described by a function $E_{\sigma} u(c(\sigma)):=\sum_{\theta_{t+1 \in A}} q_{t+1}\left(\theta_{t+1} \mid \sigma\right) \cdot u\left(c^{y}(\sigma), c^{o}\left(\left(\sigma, \theta_{t+1}\right)\right)\right)$. Here

\footnotetext{
${ }^{3}$ We could also assume that the cardinality depends on the node as long as it is uniformly bounded above.

${ }^{4}$ Thus, there is no population growth. This assumption is only made for the simplicity of exposition. It can easily, at the cost of some additional notation, be dispensed with. We will consider a growing economy in section 5 .
} 
we denote by $c(\sigma)=\left(c^{y}(\sigma),\left(c^{o}\left(\sigma^{\prime}\right)\right)_{\sigma^{\prime} \in \sigma^{+}}\right)$the consumption vector of agent $\sigma, c^{y}(\sigma)$ is his consumption in his youth, $\left(c^{o}\left(\sigma^{\prime}\right)\right)_{\sigma^{\prime} \in \sigma^{+}}$is his consumption in the different states of nature in his old age. The Bernoulli function $u: \mathbb{R}_{+}^{2} \rightarrow \mathbb{R}$ is twice continuously differentiable (in the interior of its domain), strictly increasing and with negative definite second derivative.

In his youth, each agent receives a wage income $w(\sigma)$ from inelastically supplying one unit of labor. In old age, agents receive interest payments from his savings. Given wage income $w(\sigma)$ and returns $r\left(\sigma^{\prime}\right) \in \mathbb{R}_{++}\left(\sigma^{\prime} \in \sigma^{+}\right)$to savings $s(\sigma)$, the household born in $\sigma$ solves:

$$
\begin{aligned}
\max _{\left(c^{y}(\sigma), s(\sigma),\left(c^{o}\left(\sigma^{\prime}\right)\right)_{\sigma^{\prime} \in \sigma^{+}}\right)} & \mathbb{R}_{+}^{2+S} \\
\text { s.t. } \quad c^{y}(\sigma)+s(\sigma) & =w(\sigma) \\
c^{o}\left(\sigma^{\prime}\right) & =r\left(\sigma^{\prime}\right) \cdot s(\sigma) .
\end{aligned}
$$

Since there is only one individual born per node, markets are trivially complete once an individual is born (sequentially complete markets) [see Dutta and Polemarchakis (1990)]. If there were several agents born per node, we would simply have to assume that markets are sequentially complete. All our results would still hold.

Firm The firm's problem is to decide after the shock realization at each node $\sigma$ how much capital to invest. This capital is then used to produce output at the successor nodes of $\sigma$. Given the probabilities and returns, the firm maximizes expected profits for some system of supporting prices $\psi(\sigma)$. Let $k\left(\sigma_{t}\right)$ denote the investment undertaken by the firm in state $\sigma_{t}$. The firm's problem at a node $\sigma$ at time $t$ is then as follows:

$$
\max _{k(\sigma) \geq 0} E_{\sigma}\left[\psi\left(\sigma^{\prime}\right) \cdot f\left(k(\sigma), \theta_{t+1}\right)\right]-\psi(\sigma) \cdot k(\sigma),
$$

where $E_{\sigma}\left[\psi\left(\sigma^{\prime}\right) \cdot f\left(k(\sigma), \theta_{t+1}\right)\right]=\sum_{\theta_{t+1 \in A}} q_{t+1}\left(\theta_{t+1} \mid \sigma\right) \cdot \psi\left(\sigma, \theta_{t+1}\right) \cdot f\left(k(\sigma), \theta_{t+1}\right)$.

Next, we define feasible allocations in this economy, the notion of interim Pareto optimality and a competitive equilibrium. For notational convenience allocations will sometimes be simply denoted by $(c, k)$ in the rest of the paper.

Definition 1 A feasible allocation (given initial capital $k_{-1}$ ) is a tuple $(c, k)$ $\left.=\left(c^{o}\left(\sigma_{0}\right),\left(\left(c^{y}(\sigma),\left(c^{o}\left(\sigma^{\prime}\right)\right)_{\sigma^{\prime} \in \sigma^{+}}\right)\right)_{\sigma \in \Gamma}\right),\left((k(\sigma))_{\sigma \in \Gamma}, k_{-1}\right)\right)$ such that

1. $c^{o}\left(\sigma_{0}\right)+c^{y}\left(\sigma_{0}\right)+k\left(\sigma_{0}\right)=f\left(k_{-1}, \theta_{0}\right)$, 
2. For $\sigma \in \Gamma: c^{o}\left(\sigma^{\prime}\right)+c^{y}\left(\sigma^{\prime}\right)+k\left(\sigma^{\prime}\right)=f(k(\sigma), \theta) \quad \forall \sigma^{\prime}=(\sigma, \theta) \in \sigma^{+}$.

The concept of Pareto optimality adopted in this paper is now introduced [Muench (1977), Peled (1982)]. ${ }^{5}$

Definition 2 A feasible allocation $(c, k)$ is called interim Pareto optimal if there exists no other feasible allocation $(\widehat{c}, \widehat{k})$ such that $\widehat{c}^{o}\left(\sigma_{0}\right) \geq c^{o}\left(\sigma_{0}\right)$ and $E_{\sigma} u(\widehat{c}(\sigma)) \geq E_{\sigma} u(c(\sigma))$ for all $\sigma \in \Gamma$, with at least one strict inequality.

Note that this definition considers agents born in different states as distinct agents. Then the usual concept of Pareto optimality is applied to this set of agents. This definition of optimality is also used in AMSZ. It implies that we do not call an equilibrium suboptimal if an individual could improve by insurance against the state in which he is born. This is an important assumption since an individual obviously cannot buy insurance against the state in which he is born. In this sense markets are naturally incomplete in a stochastic OLG model opening a source of welfare improvements for a government by providing insurance against the state in which an individual is born. We do not consider these improvements by the use of interim Pareto optimality as a welfare criterion. Together with the fact that markets are sequentially complete we may conclude that complete markets are an important maintained feature of our setup throughout the paper. This feature of our model distinguishes our analysis from Gordon and Varian (1988), Blanchard and Weil (1992, 2001) and Bohn (1998b) who consider ex ante Pareto-optimality and thus have a setup with incomplete markets opening a much broader insurance role for a government.

Now, we introduce the concept of a competitive equilibrium for the economy. We define a list of returns $(r(\sigma))_{\sigma \in \Gamma}$ as $r$ and a list of household incomes $(w(\sigma))_{\sigma \in \Gamma}$ as $w$.

Definition $3\left(c^{*}, s^{*}, k^{*}, r^{*}, w^{*}, \psi^{*}\right)$ is a competitive equilibrium if

1. $\left(c^{*}, k^{*}\right)$ is a feasible allocation,

2. given wages $w^{*}$ and returns $r^{*},\left(c^{*}, s^{*}\right)$ solves (1) for every household,

3. $E_{\sigma}\left[\psi^{*}\left(\sigma^{\prime}\right) \cdot f^{\prime}\left(k^{*}\left(\sigma, \theta_{t+1}\right)\right)\right]=\psi^{*}(\sigma)$ for all $\sigma \in \Gamma$ and $\sigma^{\prime}=(\sigma, \theta)$, i.e. firms maximize profits given $\psi^{*}$.

4. $k^{*}(\sigma)=s^{*}(\sigma) \forall \sigma \in \Gamma, r^{*}\left(\sigma^{\prime}\right)=f^{\prime}\left(k^{*}(\sigma), \theta_{t+1}\right), w^{*}(\sigma)=f\left(k^{*}\left(\sigma_{-1}\right), \theta_{t}\right)-$ $f^{\prime}\left(k^{*}\left(\sigma_{-1}\right), \theta_{t}\right) \cdot k^{*}\left(\sigma_{-1}\right) \forall \sigma \in \Gamma$.

\footnotetext{
${ }^{5}$ The term interim Pareto optimal is not used consistently in the literature. We follow the terminology of Demange and Laroque (2000).
} 
All conditions in this definition are standard: feasibility, utility maximization, profit maximization, market clearing and marginal productivity factor prices. Note that for a given $k^{*}$ the supporting prices in condition 3 are not uniquely determined. Note furthermore, that the solution to the firm problem will be interior due to the Inada conditions.

A convenient and standard assumption we will make is to assume that the upper bound on output $\sup _{\theta \in A}\{k \mid f(k, \theta)=k\}$ is finite, so that our economy is bounded, and therefore, all allocations will be bounded above.

\section{A New Role for a Dynamic Debt Policy}

In this section, we will give a complete characterization of cases in which a competitive equilibrium in our economy is not interim Pareto optimal. We will give an extensive interpretation of the possible inefficiencies we identify [section 3.1]. We will furthermore derive a set of sufficient conditions for suboptimality which are particularly simple to verify empirically since they are only stated in terms of bond interest rates [section 3.2]. Finally, we will explore the full scope of dynamic debt policy by deriving a second welfare theorem. This leads to the conclusion that in the case of suboptimality, the government can implement Pareto-improving and Pareto optimal allocations by providing insurance against macroeconomic risk through a dynamic debt policy although all markets are complete [section 3.3].

\subsection{Characterization of Interim Pareto Optimality}

Let us first give the following definition of a transfer pattern. This definition is intimately related to the theme at the heart of our paper: dynamic insurance through debt policy.

Definition 4 A transfer pattern $\lambda$ is a function $\lambda: \Gamma \rightarrow[0,1]$ with the following properties:

1. There exists a partition of $\Gamma: \Gamma=\Gamma_{+} \bigcup \Gamma_{0} \bigcup\left\{\sigma_{0}\right\}$ with $\Gamma_{+} \neq \emptyset$.

2. $\lambda\left(\sigma_{0}\right)=1$.

3. $\sigma \in \Gamma_{0}$ if and only if $\lambda(\sigma)=0$ and $\sigma \in \Gamma_{0}$ implies for all $\sigma^{\prime} \in \sigma^{+}$that $\sigma^{\prime} \in \Gamma_{0}$.

4. If $\sigma \in \Gamma_{+}$then $\sum_{\sigma^{\prime} \in \sigma^{+}} \lambda\left(\sigma^{\prime}\right)=1$. 
Let us give an intuitive explanation of the definition. It says that $1 . \Gamma$ can be divided into three disjoint subsets, one set of nodes $\Gamma_{0}$ where no transfers are assigned, one set of nodes $\Gamma_{+}$associated with positive transfers and the root $\sigma_{0}$. 2. As a convenient convention transfer weight one is assigned to the root. 3. If no transfers are assigned at one node then no transfers are assigned at all successor nodes of this node. 4. Most importantly, once transfers are assigned at one node $\sigma$ then they are assigned at some successor node(s) $\sigma^{\prime} \in \sigma^{+}$. Furthermore, transfers are normalized so that their weights sum up to one. The value $\lambda\left(\right.$.) of the transfer pattern can be interpreted as follows. Consider $\lambda\left(\sigma^{\prime}\right)$ and $\lambda\left(\sigma^{\prime \prime}\right)$ at two arbitrary nodes $\sigma^{\prime}, \sigma^{\prime \prime} \in \sigma^{+}$and let $T^{o}\left(\sigma^{\prime}\right)$ and $T^{o}\left(\sigma^{\prime \prime}\right)$ be the value of transfers to the old in those nodes. It then holds that $\frac{\lambda\left(\sigma^{\prime}\right)}{\lambda\left(\sigma^{\prime \prime}\right)}=\frac{T\left(\sigma^{\prime}\right)}{T\left(\sigma^{\prime \prime}\right)}$. The transfer pattern $\lambda$ thus describes the relative size of transfers in different states at one point of time. It will turn out that from an insurance perspective high $\lambda$ 's should be chosen for nodes at which a bad shock realized for the old generation.

In order to present our first result, we need one more piece of notation. We define the marginal rate of substitution between young age consumption in node $\sigma$ and old age consumption in node $\sigma^{\prime}=\left(\sigma, \theta^{\prime}\right) \in \sigma^{+}$as

$$
\operatorname{mrs}\left(\sigma, \sigma^{\prime}\right)=\frac{\sum_{\theta \in A} q(\theta \mid \sigma) \cdot u_{1}\left(c^{y}(\sigma), c^{o}(\sigma, \theta)\right)}{q\left(\theta^{\prime} \mid \sigma\right) \cdot u_{2}\left(c^{y}(\sigma), c^{o}\left(\sigma, \theta^{\prime}\right)\right)}
$$

where $u_{i}$ denotes the partial derivative with respect to the i-th argument. It specifies the amount of consumption at node $\sigma^{\prime}$ required to compensate for the loss of one consumption unit at node $\sigma$. A low marginal rate of substitution will be a crucial element in identifying states where only a low insurance benefit (compensation during old age) has to be paid to an individual in exchange for one dollar of insurance contribution (payment during young age).

Now we can state our first main result:

Theorem 5 Let $\left(c^{*}, s^{*}, k^{*}, r^{*}, w^{*}, \psi^{*}\right)$ be an interior competitive equilibrium which is bounded below. Then a necessary and sufficient condition for the competitive equilibrium allocation not to be interim Pareto-optimal is that there exists a transfer pattern $\lambda$ and a finite positive number $A$ such that for every path $\sigma^{\infty}=\left(\sigma_{0}^{\infty}, \sigma_{1}^{\infty}, \ldots\right)$ in the tree

$$
\sum_{t=0}^{\infty} \prod_{s=1}^{t} \lambda\left(\sigma_{s}^{\infty}\right) \cdot \operatorname{mrs}\left(\sigma_{s}^{\infty}, \sigma_{s-1}^{\infty}\right) \leq A<\infty .
$$

The main idea of the proof is to show that a competitive equilibrium is interim Pareto optimal if and only if there is no possibility of Pareto improvement by joint feasible 
deviations (lower consumption and investment of the young) of the initial competitive consumption-investment plan. In particular, these joint deviations make redistributive schemes possible that are not available in the analysis of infinite-horizon production problems when dynamic efficiency is considered or in pure exchange models. We have to deal with deviations that do not only involve a steady decrease in the capital stock [as in Cass (1972) under certainty and Zilcha (1990) under uncertainty] and with deviations that do not only involve pure transfers from young to old in every period [as in Balasko and Shell (1980), Okuno and Zilcha (1980) under certainty and the pure exchange analogue to our result, Chattopadhyay and Gottardi (1999)].

To understand the economic content of this characterization let us highlight how the transfer pattern will look like in order to identify a suboptimal allocation. This transfer pattern is part of an intergenerational dynamic insurance contract. Consider first the static part of this insurance and assume for simplicity that each state occurs with the same probability. The choice of the transfer pattern should be guided as the choice of any insurance contract. High benefits should be paid in bad states (states where consumption without insurance benefits is low), low or no benefits should be paid in good states (states where consumption without insurance benefits is high). Whether a state $\sigma^{\prime}$ is worse than another state $\sigma^{\prime \prime}$ can be inferred by inspecting the marginal rate of substitutions $\operatorname{mrs}\left(\sigma^{\prime}, \sigma\right)$ and $m r s\left(\sigma^{\prime \prime}, \sigma\right)$. Of course, a low marginal rate of substitution indicates low consumption and thus a bad state. So from a static insurance perspective high transfer should be paid whenever the marginal rate of substitution is low. Now recall from the interpretation of a transfer pattern that relatively high transfers correspond to high $\lambda$ 's. Taking a look at the characterization in equation (3) shows that this strategy - high $\lambda$ 's when the marginal rate of substitution is low and vice versa - is indeed useful in order to achieve convergence of the sum and thus in order to identify suboptimality of an allocation in our model.

So far we have shown that our argument is consistent with the standard static view of an insurance. These static considerations taken by themselves cannot indicate any form of suboptimality since markets are complete in our model. A truly dynamic perspective enters the picture if one realizes that the insurance benefits of one generation are raised through contributions from the next generation. Therefore, it may be a good idea to sell insurance to one generation only if subsequent generations will demand low compensation for a dollar of contributions raised from them. Let us be more specific.

Consider an individual who has exploited all insurance possibilities on private markets. He is left with aggregate (macroeconomic) risk during old age. He would be willing to pay an insurance premium for a further smoothing of his consumption across states during 
old age - for an insurance against macroeconomic risk. Suppose the government promises to smooth consumption of this individual when he is old, i.e. the government promises to pay high insurance benefits in bad states and low or no benefits in good states. How can the government keep this promise? It can try to find a second, younger individual who himself is willing to pay an insurance premium for a smoother consumption during his old age. The government then extracts an insurance premium from this second individual and pays it as an old age benefit to the first individual. When the second individual is old the government looks for a third individual etc.

Now two things have to be ensured. First, the government has to ensure that the transfers lead to a smoother consumption of the recipient of the transfer during his old age. Second, the transfers have to be financed in a way that is feasible in the long run. The characterization in theorem 5 tells us how this can be achieved. Transfers should be high along paths with low marginal rates of substitution and vice versa. This strategy makes transfers cheap in the sense that the promise to a contributor makes him better off but involves low average benefits during his old age, when he receives benefits in exchange for the contributions he paid during his young age. This mechanism establishes an uninterrupted chain of intergenerational insurance contracts. The promise made in one insurance contract can only be kept if another insurance contract with the following generation is established. The government ensures - as in a debt Ponzi scheme - that this chain of contracts is rolled over infinitely into the future.

Compare this scheme to a deterministic setting. There, the role of debt is restricted to debt Ponzi schemes which roll over safe debt infinitely into the future. The wellknown conditions for dynamic efficiency then rule out this kind of scheme. Uncertainty adds a new dimension to the role of a government. Debt may additionally serve as a means of intergenerational risk sharing. The risk that can be insured is aggregate (macroeconomic) risk. It is crucial that these risk sharing opportunities do not result from any form of market incompleteness, but from the dynamic structure of the economy. Thus, risk sharing in our model works through a mechanism that resembles the idea of a Ponzi scheme, but is more sophisticated. Instead of rolling over debt, we can interpret our scheme as one that raises contributions and then rolls over an insurance contract in exchange for the contributions. This mechanism of a sophisticated Ponzi scheme is a form of dynamic risk sharing and is provided by promises of an infinitely-lived government. 


\subsection{Suboptimality and the Term Structure of Interest Rates}

The previous theorem is very satisfactory from a purely theoretical point of view since it gives a complete characterization of Pareto optimal and thus also suboptimal equilibria. The problem faced by the characterization from a more applied point of view is the fact that the theorem is not stated in terms of observables. Neither are the marginal rates of substitution directly observable nor is the transfer pattern specified so that a certain equilibrium allocation could be tested for Pareto optimality. Furthermore, it is considered to be problematic to implement state-contingent policies and one would prefer policy instruments which are less demanding and exist in real world economies [see Aiyagari, Marcet, Sargent, Seppälä (2001) and Angeletos (2000)].

Our next result meets the shortcomings of the previous theorem and also indicates how an optimal or improving policy may look like. It highlights the applicability of the previous theorem since all the results are derived by special choices of a transfer pattern. This will become clear in the proof and in the interpretation following the theorem. The observables we choose are $n$-period bond interest rates and the corresponding policy instrument is the choice of the maturity structure. So what is the role a portfolio of non-contingent debt can play?

Consider an example with a simple policy. The government issues two-period bonds to a young (first) generation and transfers the receipts to the old generation (generation zero). When the first generation is old, the two period bonds are sold for the endogenous and state-contingent price of one period bonds to the then young (second) generation which holds these bonds until maturity. This state-contingency is beneficial for the first generation whenever the price of one period bonds is high in economic downturns and low otherwise. ${ }^{6}$ In this case, issuing two-period bonds and the implicit state contingency of the resale price helps smoothing consumption in old age. In this example only the first generation is offered an insurance whereas the second generation transfers income to their old age with the help of one-period bonds which of course yield equal returns across states. This overrolling pattern of one-period and two-period bonds is then extended infinitely into the future.

\footnotetext{
${ }^{6}$ We acknowledge that the empirical evidence on the cyclicality of the real interest rates tends to be in favor of countercyclicality. This in turn implies a positive correlation between bond prices and output. However, we do not intend to propagate a specific restructuring of the debt portfolio in our example. Its only objective is to provide the intuition underlying the two results in this section. More elaborate policies may be chosen whenever one of the criteria indicates suboptimality. If urged to set an example that fits the data, we could change the above policy slightly by issuing nominal debt instead of real debt. The reason is that the empirical evidence on nominal debt is in favor of our policy, as nominal bond interest rates are contemporaneously procyclical and thus the correlation between prices of debt and output is negative [see e.g. Stock and Watson (1999), King and Watson (1995) and Fama (1990)].
} 
Consider a second example with a complete overrolling of insurance in the sense that every generation (not only every second generation as in the previous example) is provided with an insurance contract. Again the government starts issuing two period bonds to a young generation. But in the subsequent period the government buys these oneperiod bonds, of course at the prevalent market price, and finances this by issuing again two-period bonds. In this example all generations are provided with insurance against macroeconomic shocks by rolling over two-period bonds.

It is important that in this scheme the young generation provides insurance against a risk for the old generation that is undiversifiable on markets. The young generation in turn obtains insurance during old age by the newly born young generation. Due to our interim optimality criterion all agents voluntarily participate in this scheme. Of course, these are only two examples adapted to an environment with simple (negative) correlation between prices of one period bonds and output. Depending on preferences and uncertainty, encoded in prices, one can think of much more elaborate designs of debt portfolios in order to improve welfare.

Our next result states sufficient conditions in terms of observables for suboptimality. Furthermore, the implementing transfers required to derive these conditions are equal to the transfers resulting from a thoughtful issuance of multi-period bonds as sketched in the two examples. Let us first embed the notion of an $n$-period bond in our framework. Let $p(\sigma)$ be the contingent claim price of consumption at node $\sigma$. Then the gross rate of return for $n$-period bonds can be defined as $R_{n}(\sigma)=p(\sigma) / \sum_{\sigma^{\prime} \in \sigma_{n}^{+}} p\left(\sigma^{\prime}\right)$, where $\sigma_{n}^{+}$ denotes the set of nodes which succeed the node today $\sigma \in \Sigma_{t}$ in $n$ periods. ${ }^{7}$ We can now state:

\section{Theorem 6}

1. Uniform Suboptimality If the risk-free gross rate of return for $n$-period bonds $R_{n}(\sigma)$ is smaller than some constant $c<1$ at every node in a competitive equilibrium, the equilibrium allocation is not interim Pareto optimal.

2. Overrolling Safe Debt If for every path $\sigma^{\infty}$ in $\Gamma$ the expression $\sum_{t=1}^{\infty} \prod_{j=0}^{t} R_{1}\left(\sigma_{j}^{\infty}\right)$ is uniformly (over all paths) bounded, the competitive allocation is not interim Pareto optimal.

3. Selective Overrolling of Insurance If for every path $\sigma^{\infty}$ in $\Gamma$ the expression $\sum_{t=1}^{\infty} \prod_{j=0}^{t} R_{n}\left(\sigma_{j \cdot n}^{\infty}\right)$ is uniformly (over all paths) bounded, the competitive allocation

\footnotetext{
${ }^{7}$ For notational simplicity, the rate of return is given for the full $n$ periods, not as interest rate per period.
} 
is not interim Pareto optimal.

4. Complete Overrolling of Insurance If for every path $\sigma^{\infty}$ in $\Gamma$ the expression $\sum_{t=1}^{\infty} \prod_{j=1}^{t} \frac{R_{2}\left(\sigma_{j-1}^{\infty}\right)}{R_{1}\left(\sigma_{j}^{\infty}\right)}$ is uniformly (over all paths) bounded, the competitive allocation is not interim Pareto optimal.

The proposition highlights that the term structure of interest rates is an important and simple instrument to link the theoretical possibility of suboptimality to empirically testable criteria. Alternatively, we could also have derived a different sufficient condition for suboptimality in terms of contingent claims prices. Since the seminal paper by Breeden and Litzenberger (1978) it is well-known in financial economics that contingent claims prices can be recovered from option prices so that such an approach would also be testable in principle. However, in contrast to bonds, options only exist for a relatively short period in history. Therefore, we have chosen to extract the information necessary to assess the suboptimality of the economy from the term structure of interest rates .

Let us discuss the four conditions for suboptimality. Condition 1 can be easily understood if it is compared to the well-known steady state condition for suboptimality in the Diamond (1965) model. There, a steady-state equilibrium is suboptimal if and only if the real net interest rate is smaller or equal to the growth rate of the economy (which is 0 in our context since we have assumed no growth). Condition 1 which is stated for the gross interest rate can be interpreted as a generalization that holds uniformly across time and states. The criterion highlights what we mean by restrictions in terms of observables. But it is so strong that it is hardly of any empirical relevance.

Consider now condition 2 which is the starting point of our use of the term structure. The condition stated in terms of one-period bonds is equivalent to the Cass (1972) criterion for inefficiency under certainty. As is well-known, this criterion is closely related to the overrolling of risk-free debt in order to improve upon the status quo. Since this not an insurance scheme we have in mind, we will defer a discussion of this criterion to section 4.2 where we deal with debt Ponzi schemes.

Conditions 3 and 4 make use of the maturity structure of government debt. They correspond to real intergenerational insurance contracts as described in the previous section and in the examples above. Insurance is provided by making use of the endogenous state-contingency of the market-value of $n$-period bonds. To see this, recall the overrolling of two-period bonds as described in the second example above. In this scheme, the young generation in state $\sigma_{t}$, i.e. at time $t$, buys two-period bonds at price $R_{2}^{-1}\left(\sigma_{t}\right)$. Selling these bonds to the government after one period, i.e. in $t+1$, results in a payoff equal to the one-period bond price $R_{1}^{-1}\left(\sigma_{t+1}\right)$ for the then old generation, which is random 
at time $t$. The return for the household of this policy equals the ratio of these prices $R_{1}^{-1}\left(\sigma_{t+1}\right) / R_{2}^{-1}\left(\sigma_{t}\right)=R_{2}\left(\sigma_{t}\right) / R_{1}\left(\sigma_{t+1}\right)$. The key point is that this return from a time $t$ perspective is state-dependent. It shows up in condition 4 since this condition describes the overrolling of an insurance contract instead of overrolling safe debt. Therefore $\frac{R_{2}}{R_{1}}$ appears in condition 4 whereas $R_{1}$ was the relevant rate of return in condition 2 .

Now consider condition 3 for the case $n=2$ which corresponds to the first example above. Here two-period and one-period bonds are issued in alternating order. The (stochastic) return for households receiving in $\sigma_{t}$ two-period bonds is $R_{2}\left(\sigma_{t}\right) / R_{1}\left(\sigma_{t+1}\right)$ as just described. Households of the next generation receiving one-period bonds in $\sigma_{t+1}$ get a state-independent return of one unit of the consumption good in $\sigma_{t+2}$ whereas they pay $R_{1}^{-1}\left(\sigma_{t+1}\right)$ in $\sigma_{t+1}$. The product of these two returns is $R_{2}\left(\sigma_{t}\right) / R_{1}\left(\sigma_{t+1}\right) \cdot 1 / R_{1}^{-1}\left(\sigma_{t+1}\right)=$ $R_{2}\left(\sigma_{t}\right)$ which is what shows up in condition 3. This product is what old households in $\sigma_{t+2}$ receive per unit of debt issued at $\sigma_{t}$. Roughly speaking, this term measures the (stochastic) growth of debt from $\sigma_{t}$ to $\sigma_{t+2}$.

The feasibility of all our overrolling schemes is guaranteed if the respective condition in the theorem is met. A prerequisite for assessing the feasibility of any roll-over scheme is a non-exploding amount of real government debt. As we saw, the growth rate of debt is closely related to the rate of return corresponding to a particular scheme. This rate of return was given by $R_{1}$ for overrolling safe debt, by $R_{n}$ for selectively overrolling insurance and by $R_{2} / R_{1}$ for a complete overrolling of insurance. The reason why $\frac{R_{2}}{R_{1}}$ appears in some of the expressions is that what exactly matters for successfully providing insurance are the relative returns of two-period and one-period bonds. Note that with countercyclical one-period bond prices, the price of a two-period bond is larger than the expected price of holding succesively two one-period bonds: $R_{2}^{-1}\left(\sigma_{t}\right)>R_{1}^{-1}\left(\sigma_{t}\right) \cdot E_{\sigma_{t}} R_{1}^{-1}\left(\sigma_{t+1}\right)$. So convergence in our examples is more likely than with acyclical or procyclical bond prices. The lower the price of two period bonds the higher is the insurance implicit in two period bonds. Of course, one can think of many more elaborate policies making use of the whole spectrum of $n$-period bonds. We hope that the general idea and the potential applicability of our insurance scheme has become clear so far. In the next section, we will explore the full scope of debt policy.

\subsection{The Scope of Government Debt as Insurance against Macroe- conomic Risk}

In the previous sections we have identified the causes for the possible suboptimality of competitive equilibria and also pointed out some particularly simple instruments to Pareto 
improve upon a competitive equilibrium. In this section, we answer the question how much a government can achieve if it exploits the full spectrum of government debt policies. The main result of this section is that any interior suboptimal allocation can be Pareto improved through a debt policy that leads to an interim Pareto optimal allocation.

A prerequisite for the analysis in this section is the observation that the characterization in theorem 5 which was derived for an economy without a government debt also applies for an economy with government debt. Under certainty, this was already mentioned by Balasko and Shell (1981). This is important since we want to apply the analysis to and improve upon equilibria in real world economies in which considerable debt already exists.

Let us now develop our analysis step by step. First, we introduce the notion of short-run optimality. We say an allocation $(c, k)$ is short-run optimal if for every $\tau \geq 1$, the truncated allocation $(c(\sigma), k(\sigma))_{\{\sigma \in \Gamma \mid t(\sigma) \leq \tau\}}$ is Pareto optimal in the finite economy generated by truncation of the original economy with preferences of the young agents born at some node $\sigma$ at time $\tau$ given by $u(c(\sigma), k(\sigma))=c(\sigma)+k(\sigma)$.

Before we can prove a version of the second welfare theorem, namely that short run optimal allocations can be supported as a competitive equilibrium with appropriate transfers, we need one more definition. It generalizes the definition of a competitive equilibrium to a setting with transfers. In the following, $T^{y}(\sigma)$ is a transfer to the young household, $T^{o}(\sigma)$ is a transfer to the old household in node $\sigma$ and $T=\left(T^{y}, T^{o}\right)$ summarizes all transfers.

Definition 7 A competitive equilibrium with transfers is a tuple $\left(c^{*}, s^{*}, k^{*}, r^{*}, w^{*}, \psi^{*}, T^{*}\right)$ such that

1. $\left(c^{*}, k^{*}\right)$ is feasible,

2. $\left(c^{*}, s^{*}\right)$ solves

$$
\begin{aligned}
\max _{\left(c^{y}(\sigma), s(\sigma),\left(c^{o}\left(\sigma^{\prime}\right)\right)_{\sigma^{\prime} \in \sigma^{+}}\right) \in \mathbb{R}_{+}^{2+S}} E_{\sigma} u(c(\sigma)) & \\
\text { s.t. } \quad c^{y}(\sigma)+s(\sigma) & =w^{*}(\sigma)+T^{y *}(\sigma) \\
c^{o}\left(\sigma^{\prime}\right) & =r^{*}\left(\sigma^{\prime}\right) \cdot s(\sigma)+T^{o *}\left(\sigma^{\prime}\right), \quad \forall \sigma^{\prime} \in \sigma^{+}
\end{aligned}
$$

3. $E_{\sigma}\left[\psi^{*}\left(\sigma^{\prime}\right) \cdot f^{\prime}\left(k^{*}\left(\sigma, \theta_{t+1}\right)\right)\right]=\psi^{*}(\sigma)$ for all $\sigma \in \Gamma$ and $\sigma^{\prime}=(\sigma, \theta)$, i.e. firms maximize profits given $\psi^{*}$. 
4. $k^{*}(\sigma)=s^{*}(\sigma) \quad \forall \sigma \in \Gamma, r^{*}\left(\sigma^{\prime}\right)=f^{\prime}\left(k^{*}(\sigma), \theta_{t+1}\right), w^{*}(\sigma)=f\left(k^{*}\left(\sigma_{-1}\right), \theta_{t}\right)-$ $f^{\prime}\left(k^{*}\left(\sigma_{-1}\right), \theta_{t}\right) \cdot k^{*}\left(\sigma_{-1}\right) \forall \sigma \in \Gamma$.

5. $T^{y *}(\sigma)+T^{o *}(\sigma)=0 \quad \forall \sigma \in \Gamma$.

Let us now turn to our next result, a second welfare theorem:

Proposition 8 Any interior short run optimal allocation can be supported as a competitive equilibrium with transfers.

Since each interim Pareto optimal allocation is obviously short run efficient, the proposition implies that all interim Pareto optimal allocations can be supported as an equilibrium with transfers. This second welfare theorem is first of all a theoretical result. However, its relationship to (possibly non-stationary) government debt as a policy instrument is straightforward.

Remark 9 Every interim Pareto optimal allocation can be implemented with a government debt policy.

In fact, it is shown in the appendix that the necessary transfers when young $T^{y}$ in the second welfare theorem which are possibly involuntary can be implemented by voluntary purchases of government bonds. The transfers when old $T^{o}$ in the second welfare theorem can also be expressed in terms of government debt. They can be decomposed into two parts. The first part are the proceeds from savings in bonds during young age. The second part is the non-stationary component of debt. It is a transfer to the old generation financed through newly issued debt which is then rolled over perpetually, i.e. bought voluntarily every period.

Now, we want to apply the second welfare theorem in order to answer the question whether Pareto-improving debt policies exist. Therefore, we need the following proposition which shows that for each Pareto suboptimal allocation a Pareto-superior and Pareto optimal allocation exists. If this allocation is interior then, by the second welfare theorem, it can be decentralized with an appropriate debt policy.

Proposition 10 Let $(c, k)$ be a given Pareto suboptimal allocation. Then there exists another feasible allocation $(\widetilde{c}, \widetilde{k})$ such that

- $(\widetilde{c}, \widetilde{k})$ interim Pareto-dominates $(c, k)$,

- $(\widetilde{c}, \widetilde{k})$ is interim Pareto optimal. 
The results in this section indicate the full scope for Pareto-improvements through a dynamic debt policy under uncertainty. If the condition for Pareto optimality in theorem 5 is violated, a well-designed debt policy can improve the allocation of risk relative to the pure market outcome (or to some initially given government debt structure).

Let us briefly return to our introductory example, the US Social Security Trust Fund. The Trust Fund is currently held only in bonds. However, the bond composition is not guided by insurance considerations we developed in this paper. So in the case of suboptimality, how could a welfare-improving design of the bond composition in the Trust Fund look like? For example, the Trust Fund could commit to provide insurance to those generations who receive payments from the Trust Fund when the decumulation process starts, i.e., when the Trust Fund is melted down (around the year 2015). This insurance could specify relatively high payments in economic downturns which affect the retirement generation negatively. In such cases, their income could be supplemented by extra payments from the Trust Fund. These payments would have to be financed by issuing government debt with an appropriate maturity to serve the insurance needs during retirement of a younger generation etc., as described above. Recall that under the testable conditions we derived, all individuals would voluntarily participate in such a scheme if the government committed to running it infinitely. Of course, the Trust Fund is just an example of an existing institution that could be in charge of such a government debt policy scheme. Such a scheme could of course also be run through the overall government budget.

Two points are remarkable about our insurance scheme in the Diamond model under uncertainty. First, our policy scheme provides an insurance that cannot be replicated on a capital market. In fact, debt may provide insurance against macroeconomic risk which is often considered to be uninsurable. Second, extending a pure exchange model to production does not improve the possibilities of risk sharing. This is surprising because, in comparison to a pure exchange model [as in Chattopadhyay and Gottardi (1999)], the redistributional possibilities considerably improve by introducing joint consumption and investment deviations from a competitive equilibrium as a source of Pareto-improvements. However, this leaves the characterization unaffected. 


\section{Restrictions on the Set of Pareto-improving Poli- cies}

The existing literature has developed different approaches to relate the theoretical possibility of Pareto improving debt policies in the OLG model with production to empirically relevant restrictions on the set of feasible policies. We will develop these ideas in the unified framework of our model. We will discuss the notion of dynamic efficiency, a No-Ponzi-Game condition and the net-dividend criterion developed by Abel, Summers, Mankiw and Zeckhauser (1989). We will show that dynamic efficiency and the infeasibility of debt Ponzi schemes are two distinct yet only necessary conditions for Pareto optimality. They can be interpreted in our framework as tests for inefficiency for special choices of a transfer pattern. Thus, if the test does not indicate inefficiency this does not imply that we are efficient. We will relate our analysis to Abel, Summers, Mankiw and Zeckhauser (1989) arguing that the net-dividend criterion is a strong sufficient condition for interim Pareto optimality in the model of AMSZ but not in our model. We will compare the models and point out the crucial difference.

\subsection{Dynamic Efficiency}

The question guiding us in this subsection is: "What observable characteristic of a growth path signals capital overaccumulation (or its absence)?" [Cass (1972), p.201]. We will reassess a strand of literature in capital theory with a long-standing tradition, the literature on the possibility of capital overaccumulation (dynamic inefficiency) which was initiated by Malinvaud (1953) and then extended to growth models by Phelps $(1961,1965)$ and more general infinite-horizon production problems by Cass (1972) and Benveniste and Gale (1975). This possibility turned out to be crucial in the OLG framework of Diamond (1965). He showed that the introduction of government debt can cure capital overaccumulation of competitive equilibria and thus he provided a Pareto-improving role for government debt. Since then, however, many authors have taken the position that real world economies are dynamically efficient. This judgement has been considered to be common knowledge since the influential contribution by Abel, Mankiw, Summers and Zeckhauser (1989). Incorporating uncertainty in their analysis, they highlighted an important distinction that had previously been neglected: which role does the risk-free interest rate play in comparison to some risky rate of return? In particular, they pointed out that the mean real risk-free interest rate was historically lower than the real growth rate of the US economy. This comparison would be suggestive of dynamic inefficiency in a 
model without uncertainty. However, what is important for dynamic efficiency is not the risk-free interest rate but rather the marginal productivity of capital, or loosely speaking, the risky interest rate [see also Zilcha (1990) and Dechert and Yamamoto (1992)].

The purpose of this section is also to examine how the concept of dynamic efficiency is related to interim Pareto optimality under uncertainty and what implication this has in terms of restrictions on the set of Pareto-improving policy interventions. Under certainty, the concepts are equivalent, as we will obtain as a special case of one of our results. To start, we give the definition of dynamic efficiency.

Definition 11 A sequence of investment decisions $\left(k(\sigma)_{\sigma \in \Gamma}\right)$ is dynamically efficient (given initial capital $\left.k_{-1}\right)$ if there exists no other sequence of investment decisions $\left(\widehat{k}(\sigma)_{\sigma \in \Gamma}\right)$ such that

$$
\begin{gathered}
\forall \sigma \in \Gamma: f(\widehat{k}(\sigma), \theta)-\widehat{k}\left(\sigma^{\prime}\right) \geq f(k(\sigma), \theta)-k\left(\sigma^{\prime}\right) \quad \forall \sigma^{\prime}=(\sigma, \theta) \in \sigma^{+} \\
f\left(k_{-1}, \theta_{1}\right)-\widehat{k}(\sigma) \geq f\left(k_{-1}, \theta_{1}\right)-k(\sigma) \quad \forall \sigma \in \Sigma_{1}
\end{gathered}
$$

with at least one strict inequality.

Dynamic efficiency thus rules out overaccumulation of capital in the sense that a decrease in savings would allow for a permanently higher aggregate consumption level. ${ }^{8}$

Let us introduce the risky rate of return $r^{*}$, which is defined as $r^{*}\left(\sigma_{s}^{\infty}\right)=f^{\prime}\left(k\left(\sigma_{s-1}^{\infty}\right), \theta\right)$, where $\left(\sigma_{s-1}^{\infty}, \theta\right)=\sigma_{s}^{\infty}$. It can be interpreted as rate of return to the market portfolio. Furthermore, denote by $\Gamma(\widehat{\sigma})$ the tree that has $\widehat{\sigma} \in \Gamma$ as its root and includes all successor nodes of $\widehat{\sigma}$. Thus $\Gamma(\widehat{\sigma})$ is a subtree of $\Gamma$. We state the following characterization of dynamic efficiency under uncertainty in our setup. ${ }^{9}$

Theorem 12 An interior feasible allocation $\left(c^{*}, k^{*}\right)$ for which $k^{*}$ is uniformly bounded below by 0 is dynamically inefficient if and only if there exists a node $\sigma_{\tau} \in \Gamma$ and some $C>0$ such that

$$
\sum_{t=1}^{\infty} \prod_{s=0}^{t} r^{*}\left(\sigma_{s}^{\infty}\right) \leq C
$$

along every path $\sigma^{\infty}=\left(\sigma_{1}^{\infty}, \ldots, \sigma_{\tau-1}^{\infty}, \sigma^{\tau}\right), \sigma^{\tau} \in \Gamma\left(\sigma_{\tau}\right)$.

\footnotetext{
${ }^{8}$ For dynamic efficiency, necessary and sufficient conditions are usually derived with elasticity conditions on the production function [see Benveniste and Gale (1975), Mitra (1979)]. If we restrict attention to interior allocations, these conditions are satisfied in our setup.

${ }^{9}$ Both Zilcha (1990) and Dechert and Yamamoto (1992) deal with dynamic efficiency under uncertainty. Apart from a minor technicality concerning the uniform bound $C$, our result is similar to the one given by Zilcha (1990). Therefore, we omit a proof.
} 
This result can be related to theorem 5 by the choice of a special transfer pattern. Therefore, the conclusion that interim Pareto optimality implies dynamic efficiency but that the converse is not true can be derived in a simple way from our characterization [see the appendix]. Thus, under uncertainty dynamic efficiency is not sufficient for interim Pareto optimality in a competitive equilibrium. It is a strictly weaker efficiency benchmark which is related only to the production side of the economy. Since the difference between the two concepts lies in the issue of risk-sharing, the concepts coincide under certainty [see also Bose and Ray (1993)]. To see this more formally in our framework, note that under certainty the condition for interim Pareto optimality in theorem 5 reduces to $\sum_{t=1}^{\infty} \prod_{s=0}^{t} r_{s}=\infty$, because the date-event tree is degenerate in this case. This condition is equivalent to the Cass criterion for dynamic efficiency under certainty.

We summarize our findings:

\section{Remark 13}

- Under uncertainty, dynamic efficiency does not rule out (interim) Pareto-improvements.

- Under certainty, the concepts of Pareto optimality and dynamic efficiency are equivalent in a competitive equilibrium.

More details on the first remark are relegated to the appendix. The insight of this section is simply that dynamic efficiency neglects possible Pareto improvements through intergenerational dynamic risk-sharing.

\subsection{Debt Ponzi Schemes}

There is a vast theoretical and empirical literature on the sustainability of government debt policies [see for example Hamilton and Flavin (1996) and Bohn (1995) and the citations therein]. Two classes of models are mainly used to examine government debt policies. The first class of models are infinite-horizon representative consumer models. The second class of models are overlapping generations models. In the following discussion we will restrict attention to stochastic versions of those models [see for example Bohn (1991, 1995, 1999)]..$^{10}$

The infinite-horizon representative consumer model has the property that in any competitive equilibrium, the government debt policy has to satisfy budget balance in a present value sense [see e.g. Lucas and Stokey (1983)]. Such debt policies are called sustainable

\footnotetext{
${ }^{10}$ Bohn (1995) discusses and criticizes deterministic theoretical models and empirical tests about sustainability based on those models.
} 
[see Bohn (1995)]. This has the implication that debt Ponzi schemes which roll over non-vanishing debt (in present value terms), cannot occur in equilibrium. The empirical literature on government debt has thus mainly been concerned with testing necessary conditions for sustainability derived from infinite-horizon representative consumer models. The question examined is: was the observed debt policy in a country consistent with the intertemporal government budget constraint derived from a theoretical model [see Ahmed and Rogers (1995) and Bohn (1998a)]?

In contrast, in models of overlapping generations, the government does not necessarily have to respect a present value budget constraint. Thus, no kind of Ponzi scheme can be ruled out a priori by theoretical reasoning. As is well known from the literature on OLG models, this fact is closely related to the possible Pareto suboptimality of competitive equilibria. This allows for an interesting question: what kind of debt policies yield Pareto improvements in cases of suboptimal equilibria? Of course, any (improving) debt policy has to satisfy allocative feasibility, which is, however, weaker than sustainability. ${ }^{11}$ Thus, tests derived in a representative consumer setting are invalid in an OLG model. Surprisingly, we are not aware of any feasibility test for an OLG model.

We will be concerned with the question: when is a perpetual budget deficit (in the sense of a debt Ponzi scheme) not only sustainable but also Pareto-improving. Our analysis is based on the second sufficient condition for suboptimality derived in section 3.2, $\sum_{t=1}^{\infty} \prod_{s=0}^{t} R_{1}\left(\sigma_{s}^{\infty}\right)$ being uniformly bounded. The transfer pattern which yields an interim Pareto-improvement can be interpreted as safe government debt in the sense that it specifies equal compensation across states of the world in the second period of life. This follows because the boundedness of $\sum_{t=1}^{\infty} \prod_{s=0}^{t} R_{1}\left(\sigma_{s}^{\infty}\right)$ allows us to reduce the analysis to the certainty case by interpreting the uncertain second period of life as certain with marginal rate of substitution between first and second period equal to the risk-free interest rate. By doing so, one obtains along each path $\sigma^{\infty}$ an OLG model under certainty and $\sum_{t=1}^{\infty} \prod_{s=0}^{t} R_{1}\left(\sigma_{s}^{\infty}\right)$ being bounded is nothing other than the usual Cass (1972) criterion for efficiency. An improving transfer scheme therefore leads to equal transfers at each node in the second period of life. ${ }^{12}$ This argument clarifies that debt Ponzi schemes are related to the risk-free rate of return whereas dynamic efficiency is related to the risky

\footnotetext{
${ }^{11}$ We distinguish sustainable and allocative feasible. It may be the case that perpetual debt is allocative feasible but not sustainable, i.e. its value does not converge to zero, so that households are not willing to hold it in a competitive equilibrium in a infinite-horizon representative consumer model. A similar distinction is also present in Tirole (1985) who distinguishes bubbly equilibria (positive value of debt) from asymptotically bubbleless equilibria (value of debt converges to zero). Both kind of equilibria are of course feasible. However, the former are not sustainable in the sense of our definition and thus cannot occur in a infinite-horizon representative consumer model.

${ }^{12}$ The existence of an implementing government debt policy follows from the second welfare theorem.
} 
rate of return. This conceptual difference is hidden in a deterministic setting.

Note that the condition is only a sufficient condition for suboptimality obtained by the choice of one particular transfer pattern. Thus its verification does not exhaust the scope for government intervention. Note furthermore that in this section we did not say anything about Pareto optimality but only about Pareto-improving policies. At first glance it may be puzzling why tax payers are willing to carry risk that is transmitted by safe debt as in a debt Ponzi scheme since they face an uncertain income next period. The point in this section is that a debt Ponzi scheme may Pareto dominate the decentralized equilibrium. But safe debt is not necessarily optimal. Superior insurance arrangements as discussed in section 3 will typically be possible.

In summary, the previous two sections have shown that dynamic efficiency, which is often considered to rule out debt Ponzi schemes (or bubbles, see Tirole (1985)), is not a decisive feature to assess the role of debt under uncertainty. Furthermore, the analysis has revealed that dynamic efficiency and the infeasibility of debt Ponzi schemes are conceptually distinct issues.

\subsection{The Net-Dividend Criterion}

In this section, we relate our approach to the important and influential contribution by AMSZ. This comparison is crucial in order to fully understand the scope of our paper. Note that the criterion for efficiency given in AMSZ is not dynamic efficiency in the sense of capital theory (our definition). What they call dynamic efficiency is in fact interim Pareto optimality [see AMSZ, section I.B, p.5]. ${ }^{13}$ Thus, the principal theoretical result of their paper is not a sufficient condition for dynamic efficiency (in our sense), but a sufficient condition for interim Pareto optimality. Recall that the criterion states that an equilibrium is Pareto optimal if in all periods and in all states profits minus investment over the total value of market shares is uniformly bounded away from zero.

They check this criterion with a univariate time series of data. Under the assumption that one can draw inference from one (realized) path about realizations of random variables on all other paths they may indeed conclude from their model that real world economies are indeed Pareto optimal. In the appendix, we will construct an example where the observation of AMSZ is consistent with a testable sufficient criterion for suboptimality derived in our model.

So what is the key difference between the two models? Seemingly, both belong to

\footnotetext{
${ }^{13}$ They explicitly write: "Our criterion is the dynamic analogue of the standard Pareto criterion" [AMSZ, p.15].
} 
the class of OLG models. However, our model is the stochastic version of the Diamond (1965) model and thus exhibits all the well-known features of OLG models. The most important feature from a theoretical point of view is the fact that in OLG models prices need not assign a finite value to every consumption bundle. This has the economic implication that competitive equilibria need not be Pareto optimal [see Geanakoplos and Polemarchakis (1991)]. The model AMSZ adopt is an OLG model with one important additional feature. ${ }^{14}$ Households have to hold shares of the market portfolio the value of which consists of a stream of dividend payments from an infinitely-lived firm. Loosely speaking, this infinite stream leads to convergence to zero of contingent claims prices over time (which implies a high interest rate) so that the net-dividend criterion is sufficient for Pareto optimality in their model. ${ }^{15}$ This behavior of prices is not a typical feature of an OLG model, but of a representative household model. Thus, their criterion for Pareto optimality is not sufficient in our model to draw the conclusion that real world economies are Pareto optimal.

In summary, we conclude that restrictions on the set of potentially Pareto-improving policies, namely the assertion that real-world economies are dynamically efficient or the assertion that Ponzi games are not sustainable, do not suffice to conclude that there is no scope for a Pareto improving debt policy. Furthermore, we argued that empirical evidence provided by AMSZ cannot be interpreted in favor of interim Pareto optimality in our model.

\section{Empirical Evidence}

In this section we attempt to develop an empirical procedure to test whether real world economies are interim Pareto optimal. Our starting point will be a sufficient criterion for suboptimality derived in section 3.1. Recall that suboptimality follows if for any maturity $n$, the sum over the product of the $n$-period bond interest rates $\sum_{t=1}^{\infty} \prod_{s=0}^{t} R_{n}\left(\sigma_{s}^{\infty}\right)$ is bounded. We will use the interest rates on U.S government bonds with one year to maturity from 1871 to 1999 as one data source. This bond interest rate series is the only one that is available over such a long period of time. Since our model did not

\footnotetext{
${ }^{14} \mathrm{AMSZ}$ write that there are two crucial differences between their model and the standard Diamond model [AMSZ, page 3]. First, their model incorporates uncertainty and second their model uses a very general production technology. The fact that their production technology differs from ours is not responsible for the differences between our results and their results. Our simpler production technology is without loss of generality. The difference we point out is not mentioned in AMSZ.

${ }^{15}$ Formally, it can be shown that the net-dividend criterion in the presence of an infinitely-lived firm implies $\liminf _{t \rightarrow \infty} \sum_{\sigma \in \Sigma_{t}} p(\sigma)=0$, where the $p(\sigma)$ are contingent claims prices [see Demange (2001)]. This is a well-known criterion for Pareto optimality.
} 
incorporate growth for notational simplicity, we have to normalize the interest rates by the growth rate of the U.S. economy. ${ }^{16}$ What matters for the feasibility of roll-over schemes is the comparison of interest rates and growth rates. This intuition carries over from the standard Diamond model under certainty to the present model with uncertainty. Our data source is the same as in Ball, Elmendorf and Mankiw (1998). ${ }^{17}$ We extended the data until 1999.

Our procedure consists of two steps. In the first step we model the univariate process for the normalized interest rate $Y:=R /(1+g)$, where $R$ is the gross interest rate on government bonds and $g$ is the growth rate of the economy. Our second step then incorporates information about this process to deal with the convergence of the sum over the product of the normalized interest rates.

We will be brief about our first step since it is identical to the analysis in Ball, Elmendorf and Mankiw (1998). Details about the estimation procedure can be found there. The most important summary statistic for our purposes is that $E[Y]$ is 0.989 and thus below one for our sample. We find that $X:=\log [R /(1+g)]$ is well described by an $\mathrm{AR}(1)$ process. The autoregressive coeffcient ranges from 0.21 to 0.47 depending on the inclusion of dummies for the war periods. These different specifications leave our main conclusion unaffected. A Dickey-Fuller test clearly rejects the null hypothesis of a unit root. Furthermore, a Breusch-Godfrey test shows no significant serial correlation of the residuals.

Our second step takes as given that the stochastic process for the log interest rates is an $\operatorname{AR}(1)$ process. Generalizations to $\operatorname{ARMA}(p, q)$ are straightforward. What we actually only need is that the stochastic process is ergodic. ${ }^{18}$ We will now show that a sufficient condition for Pareto suboptimality is $E[X]<0$.

Let $(\Omega, \mathcal{A}, P)$ denote the probability space on which the $\varepsilon_{t}$ and $X_{t}$ are defined. For each finite family $\left\{t_{1}, t_{2}, \ldots, t_{n}\right\}$ the joint distribution of $\varepsilon_{t_{1}}, \ldots, \varepsilon_{t_{n}}$ is denoted by $P_{\varepsilon_{t_{1}}, \ldots, \varepsilon_{t_{n}}}(=$ $\left.\otimes_{i=1}^{n} P_{\varepsilon_{t_{i}}}\right)$. The Kolmogorov existence theorem implies that there exists an unique probability measure $P_{\varepsilon}$ on $\left(\mathbb{R}^{\infty}, \mathcal{B}^{\infty}\right)$, where $\mathbb{R}^{\infty}:=\times_{t=-\infty}^{\infty} S_{t}$ with $S_{t}=\mathbb{R}$ and $\mathcal{B}^{\infty}$ is the Borel $\sigma$-algebra generated by the product topology on $\mathbb{R}^{\infty}$, such that the finite dimensional distributions of $P_{\varepsilon}$ are equal to the corresponding joint distributions of $\varepsilon_{t_{1}}, \ldots, \varepsilon_{t_{n}}$, i.e. $P_{\varepsilon}\left(\pi_{t_{1}, t_{2}, \ldots, t_{n}}^{-1}\right)=P_{\varepsilon_{t_{1}}, \ldots, \varepsilon_{t_{n}}}$, where $\pi_{t_{1}, t_{2}, \ldots, t_{n}}$ denotes the projection map from $\mathbb{R}^{\infty}$ to the coordinates $t_{1}, t_{2}, \ldots, t_{n}$.

\footnotetext{
${ }^{16}$ Our boundedness assumption at the end of section 2 now applies to the normalized economy. It is thus w.l.o.g.

${ }^{17}$ We would like to thank Doug Elmendorf for providing us with the data set.

${ }^{18}$ The idea underlying this step was introduced by Zilcha (1991) in the context of dynamic efficiency.
} 
Define the shift mapping $T: \mathbb{R}^{\infty} \rightarrow \mathbb{R}^{\infty}$ by $\pi_{k}(T x)=\pi_{k+1}(x)$ for all $k \in \mathbb{Z}$. Under the assumptions made on $\varepsilon$, the shift mapping $T$ is ergodic on $\left(\mathbb{R}^{\infty}, \mathcal{B}^{\infty}, P_{\varepsilon}\right)$ (see Billingsley (1995), p.495). Now define a map $\phi: \mathbb{R}^{\infty} \rightarrow \mathbb{R}$ by

$$
\phi(x)=\left\{\begin{array}{cc}
\sum_{k=0}^{\infty} \beta^{k} \cdot \pi_{-k}(x) & \text { for all } x \text { for which the series converges } \\
0 \text { otherwise }
\end{array}\right.
$$

$\phi$ is $\mathcal{B}^{\infty}-\mathcal{B}^{1}$-measurable and integrable since $\int|\phi(x)| d P_{\varepsilon} \leq \int \sum_{k=0}^{\infty}|\beta|^{k} \cdot\left|\pi_{-k}(x)\right| d P_{\varepsilon} \underset{\text { mon.conv. }}{=}$ $\sum_{k=0}^{\infty}|\beta|^{k} \cdot \int\left|\pi_{-k}(x)\right| d P_{\varepsilon}=\sum_{k=0}^{\infty}|\beta|^{k} \cdot \int|y| d P_{\varepsilon_{-k}}<\infty$.

Because log interest rates follow an $\mathrm{AR}(1)$-process we have $X_{0}(x)=\phi(x)$. Thus, we know that an $\mathrm{AR}(1)$ process is ergodic, i.e., $X_{t}(x)=X_{0}\left(T^{t} x\right)$. Ergodicity is all we need to apply the Birkhoff Ergodic Theorem from which it follows:

$$
\frac{1}{n} \sum_{t=1}^{n} X_{t}(x)=\frac{1}{n} \sum_{t=1}^{n} X_{0}\left(T^{t} x\right) \underset{n \rightarrow \infty}{\longrightarrow} \int_{\mathbb{R}^{\infty}} X_{0}(x) d P_{\varepsilon} \quad \text { a.s. }-P_{\varepsilon} .
$$

If we thus can show that $E[X]:=\int_{\mathbb{R}^{\infty}} X_{0}(x) d P_{\varepsilon}<0$, it follows that

$$
\sum_{t=1}^{\infty} \prod_{s=1}^{t} Y_{s}(x)=\sum_{t=1}^{\infty} \exp \left[\sum_{s=1}^{t} \ln \left(Y_{s}(x)\right)\right]=\sum_{t=1}^{\infty} \exp \left[\sum_{s=1}^{t} X_{s}(x)\right]
$$

converges a.s. $-P_{\varepsilon}$, because then for $t$ sufficiently large $\sum_{s=1}^{t} X_{s}(x)<-t \delta$ for some $\delta>0$, which implies the convergence of $\sum_{t=1}^{\infty} \exp \left[\sum_{s=1}^{t} X_{s}(x)\right] .{ }^{19}$

We summarize these considerations:

Proposition 14 If the stochastic process for the log of the normalized interest rates $X_{t}:=\log \left[R_{t} /\left(1+g_{t}\right)\right]$ is ergodic (where $R$ is the gross interest rate and $g$ is the growth rate of the economy), then $E\left[X_{t}\right]<0$ implies $\sum_{t=1}^{\infty} \exp \left[\sum_{s=1}^{t} X_{s}(x)\right]$ converges a.s..

Thus, in order to apply the proposition in order to detect suboptimality, the only thing we have to show in our data is that the mean of the $X$ 's is below 0 . For our data this is indeed clearly and significantly the case [see also the summary statistics in Ball, Elmendorf and Mankiw (1998)]. We obtain a mean of -0.014. A standard hypothesis test indicates that the mean is significantly smaller than zero at a p-value of 0.053 , i.e. almost at the $5 \%$ level. Thus we can conclude that the US economy is likely not to be interim Pareto optimal.

\footnotetext{
${ }^{19}$ While our theoretical condition from proposition 6 requires uniform convergence, ergodicity gives only pathwise convergence. However, this implies uniform convergence on set of paths with measure arbitrarily close to 1 , which we regard as sufficent to conclude suboptimality in an empirical analysis.
} 
Let us briefly mention that we neglected capital taxes in the US in our analysis since we did not have access to reliable data. Including capital taxes would lower the net rate of return households earn by holding bonds. This would make our result on suboptimality even stronger. Thus our comparison of the growth rate and the pre-tax rate of return on bonds underestimates the scope for welfare improvements of a debt policy.

For the case of dynamic efficiency a similar criterion was derived by Zilcha (1991). It says that $E[\log (1+r) /(1+g)]>0$ implies dynamic efficiency. The only difference to our criterion is that the risk-free rate of return is replaced by the risky rate of return. We use the capital rental rate in the US from 1929-1997 as derived by Mulligan (2001) as the risky rate of return. ${ }^{20}$ The average rental rate for that period was 0.083 with a standard deviation of 0.0178 . When compared to the real growth rate over the same period, the data clearly indicate that the US economy is dynamically efficient. Alternative measures like stock returns do not change our conclusions.

\section{Concluding Remarks}

We started out with the question whether there is a role for government debt in a stochastic framework beyond simple Ponzi games. In other words we asked whether the stochastic Diamond OLG model provides us with a theory of a deliberate debt policy, involving bonds of various maturity instead of just one period bonds as in a deterministic model.

Our first main result (Theorem 5) together with our second welfare theorem (Proposition 8) described the scope of a welfare improving (and possibly non-stationary) debt policy. From a theoretical perspective, we gave a complete characterization of interim Pareto optimality in a stochastic Diamond OLG-model and so worked out conditions implying a role for debt policy. This result isolates a source of insurance which has been neglected in the literature so far. We have shown that the dynamic structure of an economy can be used to provide insurance against macroeconomic risk. This kind of insurance is neither ruled out by dynamic efficiency nor by the infeasibility of debt Ponzi schemes. Furthermore, it cannot be provided even on complete capital markets, which provide (complete) insurance only against diversifiable risk but not against aggregate macroeconomic risk. In addition, this intergenerational insurance contract has the important feature that it is voluntarily accepted by all individuals once they are born, i.e. not only ex ante. Our second main result (Theorem 6) provided testable criteria to assess the feasibility of such insurance. These criteria were stated in terms of bond interest rates and we have shown

\footnotetext{
${ }^{20}$ We would like to thank Casey B. Mulligan for providing us with his data set.
} 
how these criteria relate to an insurance role of multi-period bonds.

By making use of the Diamond model, we rely on the Consumption CAPM, developed first by Lucas (1978), to price assets and so multi-period bonds. We acknowledge that this kind of asset pricing is at odds with many empirical contributions. Nevertheless, we believe that our idea of sophisticated Ponzi schemes is robust to the underlying asset pricing model. But a conclusive empirical assessment awaits future research on an asset price model which fits the data better.

Angeletos (2001) considers the role of the maturity structure for fiscal policy in an important contribution to the optimal fiscal policy literature. He shows that the maturity structure can substitute for state-contingent debt. Whereas he uses the maturity structure to provide insurance to the government against fiscal shocks we use the maturity structure to provide insurance against macroeconomic shocks to the agents directly. These objectives are conflicting since insurance of the government requires low bond prices in downturns whereas insurance to the agents requires exactly the opposite. Thus, future research has to show whether smoothing tax distortions or providing insurance plays the decisive role in debt management.

Furthermore, future research should add a true monetary perspective. Such an extension seems to be necessary for a final and conclusive empirical assessment since nominal bonds are rather the rule than the exception and furthermore, the cyclical behavior of the price of real and nominal bonds differ.

In summary, we have pointed out a new role for a well-designed dynamic government debt policy: it can provide insurance against macroeconomic risk.

\section{References}

[1] Abel, Andrew B., N. Gregory Mankiw, Lawrence Summers and Richard J. Zeckhauser (1989), Assessing Dynamic Efficiency: Theory and Evidence, Review of Economic Studies 56, 1-19.

[2] Aiyagari, Rao, Albert Marcet, Thomas J. Sargent and Juha Seppälä (2001), Optimal Taxation without State-Contingent Debt, downloadable Working Paper, Universitat Pompeu Fabra.

[3] Ahmed, Shaghil and John H. Rogers (1995), Government Budget Deficits and Trade Deficits: Are Present Value Constraints Satisfied in Long-Term Data?, Journal of Monetary Economics 36, 351-74. 
[4] Angeletos, George-Marios (2000), Fiscal Policy with Non-Contingent Debt and the Optimal Maturity Structure, forthcoming Quarterly Journal of Economics.

[5] Balasko, Yves and Karl Shell (1980), The Overlapping-Generations Model, I: The Case of Pure Exchange without Money, Journal of Economic Theory 23, 281-306.

[6] Balasko, Yves and Karl Shell (1981), The Overlapping-Generations Model. II: The Case of Pure Exchange with Money, Journal of Economic Theory 24, 112-42.

[7] Benveniste, Lawrence and David Gale (1975), An Extension of Cass' Characterization of Infinite Efficient Production Programs, Journal of Economic Theory 10, 229238.

[8] Billingsley, Patrick (1995), Probability and Measure, 3rd edition, Wiley, New York.

[9] Blanchard, Olivier-Jean and Philippe Weil (1992), Dynamic Efficiency, The Riskless Rate, and Debt Ponzi Games under Uncertainty, National Bureau of Economic Research Working Paper No. 3992.

[10] Blanchard, Olivier-Jean and Philippe Weil (2001), Dynamic Efficiency, The Riskless Rate, and Debt Ponzi Games under Uncertainty, Working Paper 01-41, MIT, Department of Economics, Working Paper Series.

[11] Bohn, Henning (1991), The Sustainability of Budget Deficits with Lump-Sum and with Income-Based Taxation, Journal of Money, Credit, and Banking 23, 580-604.

[12] Bohn, Henning (1995), The Sustainability of Budget Deficits in a Stochastic Economy, Journal of Money, Credit, and Banking 27, 257-71.

[13] Bohn, Henning (1998a), The Behavior of U.S. Public Debt and Deficits, Quarterly Journal of Economics 113, 949-63.

[14] Bohn, Henning (1998b), Risk Sharing in a Stochastic Overlapping Generations Economy, University of Santa Barbara Discussion Paper, December 1998.

[15] Bohn, Henning (1999), Fiscal Policy and the Mehra-Prescott Puzzle: On the Welfare Implications of Budget Deficits When Real Interest Rates Are Low, Journal of Money, Credit, and Banking 31, 1-13.

[16] Bose, Amitava and Debraj Ray (1993), Monetary equilibrium in an overlapping generations model with productive capital, Economic Theory 3, 697-716.

[17] Breeden, Douglas T. and Robert H. Litzenberger (1978), Prices of State Contingent Claims Implicit in Option Prices, Journal of Business 51, 621-651. 
[18] Cass, David (1972), On capital overaccumulation in the aggregative, neoclassical model of economic growth: A complete characterization, Journal of Economic Theory 4, 200-223.

[19] Chattopadhyay, Subir and Piero Gottardi (1999), Stochastic OLG Models, Market Structure, and Optimality, Journal of Economic Theory 89, 21-67.

[20] Dechert, W. Davis and Kenji Yamamoto (1992), Asset Valuation and Production Efficiency in an Overlapping-Generations Model with Production Shocks, Review of Economic Studies 59, 389-405.

[21] Demange, Gabrielle (2001), On the optimality of intergenerational risk sharing, forthcoming Economic Theory. Downloadable at: http://www.delta.ens.fr/demange/olg.pdf

[22] Demange, Gabrielle and Guy Laroque (1999), Social Security and Demographic Shocks, Econometrica 67, 527-42.

[23] Diamond, Peter (1965), National Debt in a Neoclassical Growth Model, American Economic Review 55, 1127-1155.

[24] Dutta, Jayasri and Herakles Polemarchakis (1990), Asset Markets and Equilibrium Processes, Review of Economic Studies 57, 229-254.

[25] Elmendorf, Douglas and N. Gregory Mankiw (1999), Government Debt, in: J. B. Taylor and M. Woodford (editors), Handbook of Macroeconomics, Volume 1, Chapter 25, 1615-1669.

[26] Fama, Eugene (1990), Term-Structure Forecasts of Interest Rates, Inflation, and Real Returns, Journal of Monetary Economics 25, 59-76.

[27] Geanakoplos, John D. and Heraklis M. Polemarchakis (1991), Overlapping Generations, in: Hildenbrand, Werner and Hugo Sonnenschein (eds.), Handbook of mathematical economics. Volume 4. Elsevier Science, New York, 1899-1960.

[28] Gordon, Roger H. and Hal R. Varian (1988), Intergenerational Risk Sharing, Journal of Public Economics 37, 185-202.

[29] Hamilton, James D. and Marjorie A. Flavin (1986), On the Limitations of Government Borrowing: A Framework for Empirical Testing, American Economic Review 76, 808-19.

[30] King, Robert G. and Mark W. Watson (1995), Money, Prices, Interest Rate and the Business Cycle, Federal Reserve Bank of Chicago, Working Paper WP-95-10. 
This is an extended version of a paper with the same title published in Review of Economics and Statistics, Vol. LXXVIII, Number 1, (February 1996), 35-53.

[31] Lucas, Robert E., Jr. (1978), Asset prices in an exchange economy, Econometrica 46, 1429-1445.

[32] Mitra, Tapan (1979), Identifying Inefficiency in Smooth Aggregative Models of Economic Growth: A Unifying Criterion, Journal of Mathematical Economics 6, 85-111.

[33] Muench, Thomas (1977), Optimality, the Interaction of Spot and Futures Markets, and the Nonneutrality of Money in the Lucas Model, Journal of Economic Theory $15,325-344$.

[34] Malinvaud, Edmond (1953), Capital Accumulation and Efficient Allocation of Resources, Econometrica 21, 233-273.

[35] Mulligan, Casey B. (2001), Capital, Interest, and Aggregate Intertemporal Substitution during the 20th Century, University of Chicago, downloadable manuscript.

[36] Okuno, Masahiro and Itzhak Zilcha (1980), On the Efficiency of a Competitive Equilibrium in Infinite Horizon Monetary Economies, Review of Economic Studies 47, 797-807.

[37] Peled, Dan (1982), Informational Diversity over Time and the Optimality of Monetary Equilibria, Journal of Economic Theory 28, 255-74.

[38] Phelps, Edmund S. (1961), The Golden Rule of Accumulation: A Fable for Growthmen, American Economic Review 55, 638-643.

[39] Phelps, Edmund S. (1965), Second Essay on the Golden Rule of Accumulation, American Economic Review 55, 793-814.

[40] Stock, James H. and Mark W.Watson (1999), Business Cycle Fluctuations in US Macroeconomic Time Series in Handbook of Macroeconomics, Volume 1, Edited by J.B. Taylor and M.Woodford, Elsevier Science.

[41] Tirole, Jean (1985), Asset Bubbles and Overlapping Generations, Econometrica 53, 1499-1528.

[42] Zilcha, Itzhak (1990), Dynamic Efficiency in Overlapping Generations Models with Stochastic Production, Journal of Economic Theory 52, 364-79.

[43] Zilcha, Itzhak (1991), Characterizing Efficiency in Stochastic Overlapping Generations Models, Journal of Economic Theory 55, 1-16. 


\section{Technical Appendix}

\section{A Preliminary Results}

This appendix contains proofs to our results in the paper. We first prove under the compactness assumption on competitive allocations that both an upper and lower uniform quadratic bound holds (locally) for the change in old age consumption expenditure expressed in terms of changes of young age consumption expenditure, often called nonvanishing and bounded Gaussian curvature condition [see Geanakoplos and Polemarchakis (1991)]. We formulate these conditions in a slightly more general set-up than used later.

Lemma 15 Let $K \subseteq \mathbb{R}_{++}^{n}$ be a compact, convex set and $\Theta$ be a compact subset of $\mathbb{R}^{m}$. Let $u: \mathbb{R}_{+}^{n} \times \Theta \rightarrow \mathbb{R}$ be $C^{2}$, strictly increasing with a negative definite Hessian matrix in $\mathbb{R}_{++}^{n}$, i.e. $\forall x \in \mathbb{R}^{n} \backslash\{0\}$ and $y \in \mathbb{R}_{++}^{n}$, all $\theta \in \Theta$ we have

$$
x^{\prime} D^{2} u(y, \theta) x<0
$$

Assume further that first and second partial derivatives of $u$ are continuous with respect to $\theta$. Then:

1. There exists a compact convex set $K^{\prime}$ with $K \subseteq K^{\prime} \subseteq \mathbb{R}_{++}^{n}$, a constant $\underline{\rho}>0$, such that for all $x^{*} \in K, x \in K^{\prime}$ and all $\theta \in \Theta$ we have

$$
u(x, \theta) \geq u\left(x^{*}, \theta\right) \Longrightarrow D u\left(x^{*}, \theta\right)\left(x-x^{*}\right) \geq \underline{\rho}\left(x_{1}-x_{1}^{*}\right)^{2}
$$

where $x_{i}$ denotes the $i$-th component of $x$.

2. There exists a compact convex set $K^{\prime}$ with $K \subseteq K^{\prime} \subseteq \mathbb{R}_{++}^{n}$, a constant $\bar{\rho}>0$, and an $\varepsilon>0$ such that for all $x^{*} \in K, x^{\prime} \in K^{\prime}$ with $0<x_{1}^{*}-x_{1}<\varepsilon$ and $x_{-1}^{*} \geq x_{-1}=$ $\left(x_{2}, \ldots, x_{n}\right)$ and all $\theta \in \Theta$ we have

$$
D u\left(x^{*}, \theta\right)\left(x-x^{*}\right) \geq \bar{\rho}\left(x_{1}-x_{1}^{*}\right)^{2} \Longrightarrow u(x, \theta) \geq u\left(x^{*}, \theta\right) .
$$

\section{Proof.}

1. Let $x$ and $x^{*}$ be given as in the lemma. Let $K^{\prime}$ be defined as $B_{\varepsilon}(K)$, which is defined as the set of all points having distance less than $\varepsilon>0$ to $K$, for $\varepsilon$ sufficiently small 
(such an $\varepsilon$ exists by compactness of $K$ ). Then we have

$$
0 \leq u(x, \theta)-u\left(x^{*}, \theta\right)=D u\left(x^{*}, \theta\right)\left(x-x^{*}\right)+\frac{1}{2}\left(x-x^{*}\right)^{\prime} D^{2} u(\xi, \theta)\left(x-x^{*}\right)
$$

by a Taylor expansion for some $\xi \in K^{\prime}$.

By assumption, $D^{2} u(x, \theta)$ is negative definite and thus $-D^{2} u(x, \theta)$ is positive definite. Thus there is a strictly positive constant $\alpha(x, \theta)$ with $-\frac{1}{2}\left(x-x^{*}\right)^{\prime} D^{2} u(\xi, \theta)\left(x-x^{*}\right) \geq$ $\alpha(\zeta, \theta) \cdot\left\|x-x^{*}\right\|^{2}$ where $\|\cdot\|$ denotes the Euclidian norm. Further, since $u$ is twice continuously differentiable and derivatives are continuous in $\theta$, it is easy to see that $\alpha(\zeta, \theta)$ depends continuously on $\zeta$ and $\theta$ (follows from Berge maximum theorem). By compactness of $K^{\prime}$ and $\Theta$ there exists some $\underline{\rho}$ with $\alpha(\zeta, \theta) \geq \underline{\rho}>0$ for all $\xi \in K^{\prime}$ and $\theta \in \Theta$. Thus

$$
D u\left(x^{*}, \theta\right)\left(x-x^{*}\right) \geq \underline{\rho} \cdot\left\|x-x^{*}\right\|^{2} .
$$

Using the fact that $\left\|x-x^{*}\right\|^{2} \geq\left|x_{1}-x_{1}^{*}\right|^{2}$ we get

$$
D u\left(x^{*}, \theta\right)\left(x-x^{*}\right) \geq \underline{\rho} \cdot\left|x_{1}-x_{1}^{*}\right|^{2} .
$$

2. For each $x \in K$ and $\theta \in \Theta$, define $\operatorname{mrs}_{i}(x, \theta)=\frac{\frac{\partial u(x, \theta)}{\partial x_{i}}}{\frac{\partial u(x, \theta)}{\partial x_{1}}}, i=2, \ldots, n$. Since $u$ is twice continuously differentiable, $m r s_{i}(x, \theta)$ depends continuously on $x$ and $\theta$, thus $\max _{i=2, \ldots, n, x \in K} \operatorname{mrs}_{i}(x, \theta)$ is finite. Define $\mu:=2 \cdot \max _{i=2, \ldots, n, x \in K, \theta \in \Theta} m r s_{i}(x, \theta)$. For each $x \in K, \theta \in \Theta$, define $\varepsilon^{i}(x, \theta), i=2, \ldots, n$, by

$$
\begin{gathered}
\max \widehat{x}_{1} \\
\text { s.t. } u\left(x_{1}-\widehat{x}_{1}, \ldots, x_{i}+\mu \cdot \widehat{x}_{1}, \ldots, x_{n}, \theta\right) \geq u(x, \theta) .
\end{gathered}
$$

By the implicit function theorem, $\varepsilon^{i}(x, \theta)$ is strictly positive. By the Berge maximum theorem $\varepsilon(x, \theta):=\min _{i=2, \ldots, n} \varepsilon^{i}(x, \theta)$ depends continuously on $x$ and $\theta$, and thus $\varepsilon^{\prime}:=\min _{x \in K, \theta \in \Theta} \varepsilon(x, \theta)$ is strictly positive. Define $K^{\prime}$ as above with $\widetilde{\varepsilon}$. Define $\varepsilon:=$ $\min \left\{\varepsilon^{\prime}, \widetilde{\varepsilon}\right\}$.

Case 1: For a given $x^{*} \in K$, consider deviations $x$ that satisfy $0<x_{1}^{*}-x_{1}<\varepsilon$ and $\left\|x_{-1}-x_{-1}^{*}\right\| \leq \mu \cdot\left(x_{1}^{*}-x_{1}\right), x_{-1} \geq x_{-1}^{*}$, where $x_{-1}=\left(x_{2}, \ldots, x_{n}\right)$. Note that $\left\|x-x^{*}\right\|=\left(\left(x_{1}^{*}-x_{1}\right)^{2}+\left\|x_{-1}-x_{-1}^{*}\right\|^{2}\right)^{\frac{1}{2}} \leq\left|x_{1}^{*}-x_{1}\right| \cdot\left(1+\frac{1}{\mu}\right)^{\frac{1}{2}}$. 
First, we have

$$
u(x, \theta)-u\left(x^{*}, \theta\right)=D u\left(x^{*}, \theta\right)\left(x-x^{*}\right)+\frac{1}{2}\left(x-x^{*}\right)^{\prime} D^{2} u(\zeta, \theta)\left(x-x^{*}\right)
$$

by a Taylor expansion. By assumption, $D^{2} u(\zeta, \theta)$ is negative definite, thus by a routine application of the Weierstrass maximum theorem there is a negative constant $a(\zeta, \theta)$ such that

$$
\frac{1}{2}\left(x-x^{*}\right)^{\prime} D^{2} u(\zeta, \theta)\left(x-x^{*}\right) \geq a(\zeta, \theta)\left\|x-x^{*}\right\|^{2}
$$

for all $x-x^{*} \in \mathbb{R}^{n}$.

Again, $a(\zeta, \theta)$ is continuous in $\zeta$ and $\theta$, and since the $\zeta$ are chosen from the compact set $K^{\prime} \subseteq \mathbb{R}_{++}^{n}$ and $\theta$ from the compact set $\Theta$, there is negative real number $a$ with $a(\zeta, \theta) \cdot\left\|x-x^{*}\right\|^{2} \geq a\left\|x-x^{*}\right\|^{2}$. Now, using that $\left\|x-x^{*}\right\| \leq\left|x_{1}^{*}-x_{1}\right| \cdot\left(1+\frac{1}{\mu}\right)^{\frac{1}{2}}$, we get

$$
u(x, \theta)-u\left(x^{*}, \theta\right) \geq D u\left(x^{*}, \theta\right)\left(x-x^{*}\right)-\bar{\rho} \cdot\left|x_{1}^{*}-x_{1}\right|^{2},
$$

with $\bar{\rho}:=\left|a \cdot\left(1+\frac{1}{\mu}\right)\right|$.

For deviations satisfying $0<x_{1}^{*}-x_{1}<\varepsilon$ and $\left\|x_{-1}-x_{-1}^{*}\right\| \leq \mu \cdot\left(x_{1}^{*}-x_{1}\right), x_{-1} \geq x_{-1}^{*}$ we thus have that the validity of

$$
D u\left(x^{*}, \theta\right)\left(x-x^{*}\right) \geq \bar{\rho} \cdot\left(x_{1}^{*}-x_{1}\right)^{2}
$$

implies $u(x, \theta)-u\left(x^{*}, \theta\right) \geq 0$.

Case 2: We next claim that for deviations taking the form $0<x_{1}^{*}-x_{1}<\varepsilon$ and $\left\|x_{-1}-x_{-1}^{*}\right\|>\mu \cdot\left(x_{1}^{*}-x_{1}\right), x_{-1} \geq x_{-1}^{*}$, the statement $u(x, \theta) \geq u\left(x^{*}, \theta\right)$ is always true for all $\theta \in \Theta$.

To see this, note that for all $x^{i}, i=2, \ldots, n$, with $x^{i}=\left(x_{1}, x_{2}^{*}, \ldots, x_{i}, \ldots, x_{n}^{*}\right)$ and $0<x_{1}^{*}-x_{1}<\varepsilon$ and $\left|x_{i}^{*}-x_{i}\right|=\mu \cdot\left(x_{1}^{*}-x_{1}\right)$ we have by definition of $\varepsilon$ and $\mu$ that $u\left(x^{i}, \theta\right) \geq u\left(x^{*}, \theta\right)$. By the strict concavity of $u$ (which is a consequence of the negative definiteness of its Hessian), it follows that $u\left(\sum_{i=2}^{n} \lambda_{i} x^{i}, \theta\right) \geq \sum_{i=2}^{n} \lambda_{i} u\left(x^{i}, \theta\right) \geq$ $u\left(x^{*}, \theta\right)$ for $\sum \lambda_{i}=1, \lambda_{i} \geq 0$.

Since $\left\|\left(\sum \lambda_{i} x^{i}\right)_{-1}-x_{-1}^{*}\right\| \leq \sum \lambda_{i}\left\|x_{-1}^{i}-x_{-1}^{*}\right\|=\mu \cdot\left(x_{1}^{*}-x_{1}\right)$, for every deviation $x$ with $0<x_{1}^{*}-x_{1}<\varepsilon$ and $\left\|x_{-1}-x_{-1}^{*}\right\|=\mu \cdot\left(x_{1}^{*}-x_{1}\right), x_{-1} \geq x_{-1}^{*}$ there exists a convex combination $\left(\lambda_{2}, \ldots, \lambda_{n}\right)$ of the $x^{i}$ corresponding to $x_{1}^{*}-x_{1}$ (i.e. $x_{1}^{i}=x_{1}$ ) for which $x \geq \sum \lambda_{i} x^{i}$. Thus by monotonicity of preferences we have $u(x, \theta) \geq u\left(x^{*}, \theta\right)$ 
for such deviations. For deviations $x$ with $0<x_{1}^{*}-x_{1}<\varepsilon$ and $\left\|x_{-1}-x_{-1}^{*}\right\|>$ $\mu \cdot\left(x_{1}^{*}-x_{1}\right), x_{-1} \geq x_{-1}^{*}$ monotonicity applied again gives $u(x, \theta) \geq u\left(x^{*}, \theta\right)$. This completes the proof.

The lemma can now be used to derive the non-vanishing and bounded Gaussian curvature conditions needed for the proof of our main theorem. ${ }^{21}$ Preferences are given by $U=U(c(\sigma))=E_{\sigma} u(c(\sigma))=\sum_{\theta_{t+1 \in A}} q_{t+1}\left(\theta_{t+1} \mid \sigma\right) \cdot u\left(c^{y}(\sigma), c^{o}\left(\left(\sigma, \theta_{t+1}\right) ; \sigma\right)\right)$. The parameter space $\Theta$ is here assumed to be a compact subset of the $S-1$ dimensional unit simplex which does not include the boundary. With this interpretation of $\Theta$ and the assumptions made on $u$, it is easy to see that the assumption of the lemma are satisfied for $U .^{22}$

Given an expression of the form

$$
D U\left(c^{*}(\sigma)\right)\left(c(\sigma)-c^{*}(\sigma)\right) \geq \alpha \cdot\left(c^{* y}(\sigma)-c^{y}(\sigma)\right)^{2}
$$

with $\alpha>0$, denote by $D U\left(c^{*}(\sigma)\right)_{1}$ the first partial derivative with respect to youth consumption, $D U\left(c^{*}(\sigma)\right)_{-1}$ the vector of partial derivatives from the $S$ states in old age. Similarly we will by $(c(\sigma))_{-1}$ denote the vector of old age consumption bundles. Then we have:

$D U\left(c^{*}(\sigma)\right)_{-1}\left(c(\sigma)-c^{*}(\sigma)\right)_{-1} \geq-D U\left(c^{*}(\sigma)\right)_{1}\left(c^{y}(\sigma)-c^{* y}(\sigma)\right)+\alpha \cdot\left(c^{* y}(\sigma)-c^{y}(\sigma)\right)^{2}$.

Since competitive allocations are from a compact set we have $\gamma \geq D U\left(c^{*}(\sigma)\right)_{1}$ for all $c^{*}$ and some $\gamma$. Now

$$
\frac{D U\left(c^{*}(\sigma)\right)_{-1}}{D U\left(c^{*}(\sigma)\right)_{1}}\left(c(\sigma)-c^{*}(\sigma)\right)_{-1} \geq-\left(c^{y}(\sigma)-c^{* y}(\sigma)\right)+\frac{\alpha}{\gamma} \cdot\left(c^{* y}(\sigma)-c^{y}(\sigma)\right)^{2} .
$$

Multiplying with the contingent-claims-price $p(\sigma)>0$, we get

$$
\sum p\left(\sigma^{\prime}\right) \cdot\left(c^{o}\left(\sigma^{\prime}\right)-c^{* o}\left(\sigma^{\prime}\right)\right) \geq-p(\sigma)\left(c^{y}(\sigma)-c^{* y}(\sigma)\right)+\rho \cdot \frac{1}{p(\sigma)} \cdot\left|p(\sigma)\left(c^{* y}(\sigma)-c^{y}(\sigma)\right)\right|^{2} .
$$

\footnotetext{
${ }^{21}$ In the proof we only use the non-vanishing Gaussian curvature condition. The bounded Gaussian curvature condition is needed to show that the condition stated in the main theorem implies the existence of Pareto improvements.

${ }^{22}$ That $D^{2} U(x(\sigma))$ is negative definite follows from a straightforward computation, since $z^{\prime} D^{2} U(x(\sigma)) z$ for any $z \in \mathbb{R}^{S+1}$ equals the convex combination of the corresponding quadratic forms for the $u(x(\sigma ; \sigma), x(\sigma, \theta) ; \sigma)$ for all $\theta \in A$.
} 
with $\rho=\frac{\alpha}{\gamma}$. Here we use the fact that the relative contingent-claims-prices equal marginal rates of substitution in a competitive equilibrium. This is the desired form of the equation leading to the Gaussian curvature conditions below. Since the set of competitive allocations is compact and bounded below in the positive orthant, by identifying $K$ with the convex hull of competitive allocations allows us to derive the non-vanishing and bounded Gaussian curvature condition from the primitives of the model.

- non-vanishing Gaussian curvature: there exists a $\underline{\rho}>0$ and a $\delta>0$, such that for any interior competitive equilibrium $\left(c^{*}, k^{*}, p^{*}\right)$, for all feasible allocations $\left(\widehat{c}, k^{*}\right) \in K^{\prime}$, where $K^{\prime}=B_{\delta}(K)$, when $K$ is the convex hull of the set of competitive allocations, $\forall \sigma \in \Gamma$,

$$
\begin{aligned}
U_{\sigma}(\widehat{c}(\sigma)) & \geq U_{\sigma}(c(\sigma)) \\
& \Longrightarrow \sum_{\sigma^{\prime} \in \sigma^{+}} \delta_{2}\left(\sigma^{\prime}, \sigma\right) \geq-\delta_{1}(\sigma)+\underline{\rho} \frac{\left(\delta_{1}(\sigma)\right)^{2}}{p^{*}(\sigma)}
\end{aligned}
$$

where $\delta_{1}(\sigma)=p^{*}(\sigma) \cdot\left[\widehat{c}^{y}(\sigma)-c^{* y}(\sigma)\right]$ and $\delta_{2}\left(\sigma^{\prime}, \sigma\right)=p^{*}\left(\sigma^{\prime}\right) \cdot\left[\widehat{c}^{o}\left(\sigma^{\prime}\right)-c^{* o}\left(\sigma^{\prime}\right)\right]$ for $\sigma^{\prime} \in \sigma^{+} . \underline{\rho}$ is called the lower curvature coefficient.

- bounded Gaussian curvature: there exists a $\bar{\rho}>0$ and a $\delta^{\prime}>0$ such that for any interior competitive equilibrium $\left(c^{*}, k^{*}, p^{*}\right)$ for all feasible allocations $\left(\widehat{c}, k^{*}\right) \in K^{\prime}$, where $K^{\prime}=B_{\delta^{\prime}}(K)$, when $K$ is the convex hull of the set of competitive allocations, with $\widehat{c}^{o}\left(\sigma^{\prime}\right) \geq c^{* o}\left(\sigma^{\prime}\right)$ for all $\sigma^{\prime} \in \sigma^{+}$, we have for all $\sigma \in \Gamma$

$$
\begin{aligned}
\sum_{\sigma^{\prime} \in \sigma^{+}} \delta_{2}\left(\sigma^{\prime}, \sigma\right) & \geq-\delta_{1}(\sigma)+\bar{\rho} \frac{\left(\delta_{1}(\sigma)\right)^{2}}{p^{*}(\sigma)} \\
& \Longrightarrow U_{\sigma}(\widehat{c}(\sigma)) \geq U_{\sigma}(c(\sigma))
\end{aligned}
$$

where $\delta_{1}(\sigma)=p^{*}(\sigma) \cdot\left[\widehat{c}^{y}(\sigma)-c^{* y}(\sigma)\right]<0$ and $\delta_{2}\left(\sigma^{\prime}, \sigma\right)=p^{*}\left(\sigma^{\prime}\right) \cdot\left[\widehat{c}^{o}\left(\sigma^{\prime}\right)-c^{* o}\left(\sigma^{\prime}\right)\right]$ for $\sigma^{\prime} \in \sigma^{+} . \bar{\rho}$ is called the upper curvature coefficient.

Next, we state a technical lemma which follows from a standard elasticity condition about the production function [see Mitra (1979)]. We will show and use in the proof of the following lemma that such a condition is satisfied in our context. The lemma gives a quadratic term lower bound for changes in the value of production due to changes in investment behavior similar to the non-vanishing Gaussian curvature assumption for the utility functions. 
Lemma 16 Given the boundedness of the economy, the following holds for all sufficiently small $0<\delta<k(\sigma)<\sup _{\theta \in A}\{k \mid f(k, \theta)=k\}$ for all $\sigma \in \Gamma$ and a price system $p$ consistent with $k(\sigma)$ :

$$
\sum_{\sigma^{\prime} \in \sigma^{+}} p\left(\sigma^{\prime}\right) \cdot\left[f\left(k(\sigma), \theta_{t+1}\right)-f\left(k(\sigma)-\delta, \theta_{t+1}\right)\right] \geq p(\sigma) \cdot \delta+c \cdot \frac{(p(\sigma) \cdot \delta)^{2}}{p(\sigma)}
$$

for some constant $c>0$.

Proof.

$$
\begin{gathered}
\sum_{\sigma^{\prime} \in \sigma^{+}} p\left(\sigma^{\prime}\right) \cdot\left[f\left(k(\sigma), \theta_{t+1}\right)-f\left(k(\sigma)-\delta, \theta_{t+1}\right)\right] \\
=\sum_{\sigma^{\prime} \in \sigma^{+}} p\left(\sigma^{\prime}\right) \cdot f^{\prime}\left(k(\sigma), \theta_{t+1}\right) \cdot \delta \cdot\left[1+\frac{f\left(k(\sigma), \theta_{t+1}\right)-f\left(k(\sigma)-\delta, \theta_{t+1}\right)}{f^{\prime}\left(k(\sigma), \theta_{t+1}\right) \cdot \delta}-1\right] \\
\geq \sum_{\sigma^{\prime} \in \sigma^{+}} p\left(\sigma^{\prime}\right) \cdot f^{\prime}\left(k(\sigma), \theta_{t+1}\right) \cdot \delta \cdot\left(1+\frac{m \cdot \delta}{k(\sigma)}\right) \\
=p(\sigma) \cdot \delta \cdot\left(1+\frac{m \cdot \delta}{k(\sigma)}\right) \geq p(\sigma) \cdot \delta+c \cdot \frac{(p(\sigma) \cdot \delta)^{2}}{p(\sigma)},
\end{gathered}
$$

where the last inequality follows from the fact that the capital stock is bounded below and the last equality follows from the first order condition of the firm.

To see that $\frac{f\left(k(\sigma), \theta_{t+1}\right)-f\left(k(\sigma)-\delta, \theta_{t+1}\right)}{f^{\prime}\left(k(\sigma), \theta_{t+1}\right) \cdot \delta}-1 \geq m>0$, note that for some $\xi(\sigma) \in(k(\sigma)-\delta, k(\sigma))$

$$
f\left(k(\sigma)-\delta, \theta_{t+1}\right)=f\left(k(\sigma), \theta_{t+1}\right)-f^{\prime}\left(k(\sigma), \theta_{t+1}\right) \cdot \delta+\frac{1}{2} \cdot f^{\prime \prime}\left(\xi(\sigma), \theta_{t+1}\right) \cdot \delta^{2} .
$$

This implies that

$$
\begin{gathered}
f\left(k(\sigma), \theta_{t+1}\right)-f\left(k(\sigma)-\delta, \theta_{t+1}\right)-f^{\prime}\left(k(\sigma), \theta_{t+1}\right) \cdot \delta \\
=\frac{1}{2} \cdot-\frac{f^{\prime \prime}\left(\xi(\sigma), \theta_{t+1}\right)}{f^{\prime}\left(k(\sigma), \theta_{t+1}\right)} \cdot k(\sigma) \cdot \frac{f^{\prime}\left(k(\sigma), \theta_{t+1}\right)}{k(\sigma)} \cdot \delta^{2} .
\end{gathered}
$$

Now note that $\frac{1}{2} \cdot-\frac{f^{\prime \prime}\left(\xi(\sigma), \theta_{t+1}\right)}{f^{\prime}\left(k(\sigma), \theta_{t+1}\right)} \cdot k(\sigma) \geq-f^{\prime \prime}\left(\xi(\sigma), \theta_{t+1}\right) \cdot \frac{1}{2} \cdot \frac{\underline{k}}{f^{\prime}(\underline{k}, \bar{\theta})}$ and since $\xi(\sigma)$ is bounded above and away from zero (this follows because by strict convexity of the economy we can w.l.o.g. assume that the improving allocation is bounded away from zero), there is some $m>0$ such that $-f^{\prime \prime}\left(\xi(\sigma), \theta_{t+1}\right) \cdot \frac{1}{2} \cdot \frac{\underline{k}}{f^{\prime}(\underline{k}, \bar{\theta})} \geq m$ 


\section{B Theorem 5}

Proof. If condition (3) in the theorem holds, then with the previous lemma it is straightforward from Chattopadhyay and Gottardi (1999) that the allocation is not interim Pareto optimal. To prove the result of the theorem it therefore remains to be shown that joint deviations from the equilibrium allocation, i.e. deviations involving redistribution and/or changes in the production plan, cannot be Pareto-improving. The proof is completed by the following three steps. Step 1 and step 2 we use short run optimality to show that an improving allocation does w.l.o.g. not involve an increase in saving and young age consumption. Step 3 then uses a generalized Cass type argument to show that nonoptimality implies condition (3).

Step 1: We will show that we can w.l.o.g. assume that an improving allocation has no increase in saving at any point of time at any node in the tree. We first show that by short run optimality we can w.l.o.g. assume that an improving allocation never begins with an increase in saving. Then we show inductively that we can restrict attention to improving allocations for which there is also no increase in saving at later nodes.

Suppose there is an increase in savings at time $t$ at node $\sigma=\left(\theta_{0}, \ldots, \theta_{t}\right)$ and that node $\sigma$ is among the first nodes (in terms of time) at which there is an increase in saving. Consider the individual born at this node with utility function $E_{\sigma} u(c(\sigma))$. Then there must be a decrease in the youth consumption of this individual which is defined by the amount of increase in saving. So let $\widehat{c}^{y}(\sigma)$ denote the youth consumption in node $\sigma$ after the increase in saving and let $c^{* y}(\sigma)$ denote the equilibrium consumption when young. Similarly, let $\widehat{k}(\sigma)$ be the capital stock in the deviating allocation and let $k^{*}(\sigma)$ be the competitive equilibrium capital stock. Since the new allocation is supposed to be Paretoimproving, we must have for a sufficiently small change by the non-vanishing Gaussian curvature condition:

$$
\sum_{\sigma^{\prime} \in \sigma^{+}} \delta_{2}\left(\sigma^{\prime}, \sigma\right) \geq-\delta_{1}(\sigma)+\underline{\rho} \frac{\left(\delta_{1}(\sigma)\right)^{2}}{p(\sigma)}
$$

Noting that $\widehat{k}(\sigma)-k^{*}(\sigma)=-\left(\widehat{c}^{y}(\sigma)-c^{* y}(\sigma)\right)>0$, using the first order condition of the firm problem and neglecting the last term on the right hand side gives:

$$
\sum_{\sigma^{\prime} \in \sigma^{+}} p\left(\sigma^{\prime}\right) \cdot\left[\widehat{c}^{o}\left(\sigma^{\prime}\right)-c^{* o}\left(\sigma^{\prime}\right)\right]>\sum_{\sigma^{\prime} \in \sigma^{+}} p\left(\sigma^{\prime}\right) \cdot f^{\prime}\left(k^{*}(\sigma), \theta\right) \cdot\left[\widehat{k}(\sigma)-k^{*}(\sigma)\right] .
$$


Thus, due to the strict concavity of the production function, we have

$$
\sum_{\sigma^{\prime} \in \sigma^{+}} p\left(\sigma^{\prime}\right) \cdot\left[\widehat{c}^{o}\left(\sigma^{\prime}\right)-c^{* o}\left(\sigma^{\prime}\right)\right]>\sum_{\sigma^{\prime} \in \sigma^{+}} p\left(\sigma^{\prime}\right) \cdot\left[f(\widehat{k}(\sigma), \theta)-f\left(k^{*}(\sigma), \theta\right)\right] .
$$

The value of the necessary increase in tomorrow's consumption is strictly larger than the increase in tomorrow's production induced by the increase in saving. This result shows that a Pareto-improving new allocation w.l.o.g. never begins with an increase in saving.

Now suppose that there has been no increase in saving at the predecessor nodes of node $\sigma$. Thus the output $f\left(\widehat{k}\left(\sigma_{-1}\right), \theta\right)$ is less than or equal to $f\left(k^{*}\left(\sigma_{-1}\right), \theta\right)$. If we have $\widehat{k}(\sigma)>k^{*}(\sigma)$ and $\widehat{c}^{y}(\sigma) \geq c^{* y}(\sigma)$, then it will also be a feasible improvement to set the deviating allocation equal to the $\left(c^{*}, k^{*}\right)$ allocation at successor nodes of $\sigma$. If $\widehat{k}(\sigma)>k^{*}(\sigma)$ and $\widehat{c}^{y}(\sigma)<c^{* y}(\sigma)$ with $-\left(\widehat{c}^{y}(\sigma)-c^{* y}(\sigma)\right) \leq \widehat{k}(\sigma)-k^{*}(\sigma)$, then taking the $\left(c^{*}, k^{*}\right)$ allocation for successor nodes of $\sigma$ and giving $\widehat{k}(\sigma)-k^{*}(\sigma)+\left(\widehat{c}^{y}(\sigma)-c^{* y}(\sigma)\right)$ to the old generation at $\sigma$ is also feasible and improving.

In the remaining case $\widehat{k}(\sigma)>k^{*}(\sigma)$ and $\widehat{c}^{y}(\sigma)<c^{* y}(\sigma)$ with $-\left(\widehat{c}^{y}(\sigma)-c^{* y}(\sigma)\right)>$ $\widehat{k}(\sigma)-k^{*}(\sigma)$, consider the allocation $(\widetilde{c}, \widetilde{k})$ with $\widetilde{c}^{y}(\sigma)=\widehat{c}^{y}(\sigma)+\widehat{k}(\sigma)-k^{*}(\sigma)$,

$$
\widetilde{c}^{o}\left(\sigma^{\prime}\right)=\left\{\begin{array}{c}
\widehat{c}^{o}\left(\sigma^{\prime}\right)+f\left(k^{*}(\sigma), \theta\right)-f(\widehat{k}(\sigma), \theta) \text { if this expression is } \geq c^{* o}\left(\sigma^{\prime}\right) \\
\widetilde{c}^{o}\left(\sigma^{\prime}\right)=c^{* o}\left(\sigma^{\prime}\right) \text { otherwise }
\end{array}\right.
$$

and keeping savings at the original level $k^{*}(\sigma)$, i.e. $\widetilde{k}(\sigma)=k^{*}(\sigma)$, returning to the $\left(c^{*}, k^{*}\right)$ allocation for nodes $\sigma^{\prime} \in \sigma^{+}$for which $\widetilde{c}^{o}\left(\sigma^{\prime}\right)=c^{* o}\left(\sigma^{\prime}\right)$, and staying at the deviating allocation $(\widehat{c}, \widehat{k})$ for the remaining nodes of $\sigma^{+}$. This new allocation $(\widetilde{c}, \widetilde{k})$ is feasible. Furthermore $\widetilde{c}^{y}(\sigma)<c^{* y}(\sigma)$ and $\widetilde{c}^{o}\left(\sigma^{\prime}\right) \geq c^{* o}\left(\sigma^{\prime}\right), \sigma^{\prime} \in \sigma^{+}$. Therefore, if $\widetilde{m r s}\left(\sigma^{\prime}, \sigma\right)$ denotes the marginal rate of substitution between $\sigma^{\prime}$ and $\sigma$ at the $(\widetilde{c}, \widetilde{k})$ allocation, by strict concavity of the utility function, we have $\frac{1}{m r s\left(\sigma^{\prime}, \sigma\right)}<\frac{p\left(\sigma^{\prime}\right)}{p(\sigma)}$. By concavity of the production function, we have $f(\widehat{k}(\sigma), \theta)-f\left(k^{*}(\sigma), \theta\right) \leq f^{\prime}\left(k^{*}(\sigma), \theta\right) \cdot\left[\widehat{k}(\sigma)-k^{*}(\sigma)\right]$. Combining this with the first order condition for the firm problem, we obtain

$$
\begin{gathered}
\widehat{k}(\sigma)-k^{*}(\sigma)=\sum_{\sigma^{\prime} \in \sigma^{+}} \frac{p\left(\sigma^{\prime}\right)}{p(\sigma)} \cdot f^{\prime}\left(k^{*}(\sigma), \theta\right) \cdot\left[\widehat{k}(\sigma)-k^{*}(\sigma)\right] . \\
>\sum_{\sigma^{\prime} \in \sigma^{+}} \frac{1}{\widehat{m r s}\left(\sigma^{\prime}, \sigma\right)} \cdot\left[f(\widehat{k}(\sigma), \theta)-f\left(k^{*}(\sigma), \theta\right)\right]
\end{gathered}
$$

Since $\widetilde{k}(\sigma)=k^{*}(\sigma)$, the marginal rate of transformation in the $(\widetilde{c}, \widetilde{k})$ allocation 
remains the same as in the original allocation. Since $\frac{1}{\overline{m r} s\left(\sigma^{\prime}, \sigma\right)}<\frac{p\left(\sigma^{\prime}\right)}{p(\sigma)}$, it follows by a short run optimality argument similar to the one used to prove that a deviating allocation can never begin with an increase in saving that any increase in saving cannot be improving for an agent born in node $\sigma$. At nodes $\sigma^{\prime} \in \sigma^{+}$at which $\widetilde{c}^{o}\left(\sigma^{\prime}\right)=c^{* o}\left(\sigma^{\prime}\right)$, the young generation gets the same as in the original $\left(c^{*}, k^{*}\right)$ allocation, at the other nodes from $\sigma^{+}$, the young generation gets the same as under the $(\widehat{c}, \widehat{k})$ allocation. (Note that the saving $\widehat{k}\left(\sigma^{\prime}\right)$ is still feasible for such nodes.) So w.l.o.g. we can assume that there is no increase in savings.

Step 2: But then it follows that we can also w.l.o.g. assume that youth consumption never increases when an improving allocation exists. This follows from short run optimality of the competitive equilibrium by a similar argument as in the first part of step 1.

Step 3: Assume a Pareto improvement is possible. Since the economy is bounded above and strictly convex, we can assume that the deviating allocation lies coordinatewise in a compact set $B_{\delta}(K)$, where $K$ is the set of competive allocations, for some $\delta>$ 0 sufficiently large. ${ }^{23}$ Consider the following identity, which follows from the resource constraint $c^{o}\left(\sigma^{\prime}\right)+c^{y}\left(\sigma^{\prime}\right)+k\left(\sigma^{\prime}\right)=f(k(\sigma), \theta) \quad \forall \sigma^{\prime}=(\theta, \sigma) \in \sigma^{+}$:

$$
-\Delta c^{y}\left(\sigma^{\prime}\right)-\Delta k\left(\sigma^{\prime}\right)=\Delta c^{o}\left(\sigma^{\prime}\right)-\Delta f(k(\sigma), \theta),
$$

where $\Delta c^{o}\left(\sigma^{\prime}\right)=\left(\widehat{c}^{o}\left(\sigma^{\prime}\right)-c^{* o}\left(\sigma^{\prime}\right)\right)$ etc. if $\left(c^{*}, k^{*}\right)$ is the initial competitive equilibrium allocation and $(\widehat{c}, \widehat{k})$ is the new interim Pareto-improving allocation. If we define $\Delta \varepsilon\left(\sigma^{\prime}\right)=-\Delta k\left(\sigma^{\prime}\right) \geq 0$ as the dissaving at node $\sigma^{\prime}$ when changing to the new allocation, which is by the argument made above (Step 1) always nonnegative, and $\Delta a\left(\sigma^{\prime}\right)=-\Delta c^{y}\left(\sigma^{\prime}\right) \geq 0$ as the decrease in youth consumption (Step 2) when changing to the new allocation, we have as transfers to the old $\Delta a\left(\sigma^{\prime}\right)+\Delta \varepsilon\left(\sigma^{\prime}\right) \geq 0$ and thus

$$
\Delta a\left(\sigma^{\prime}\right)+\Delta \varepsilon\left(\sigma^{\prime}\right)=\Delta c^{o}\left(\sigma^{\prime}\right)-\Delta f(k(\sigma), \theta) .
$$

Consider all nodes $\sigma^{\prime} \in \sigma^{+}$for which $\Delta a\left(\sigma^{\prime}\right)+\Delta \varepsilon\left(\sigma^{\prime}\right)>0$. Since the improving allocation $(\widehat{c}, \widehat{k})$ must at some node $\widetilde{\sigma}$ be different from the initial one we must have $\Delta a(\widetilde{\sigma})+$ $\Delta \varepsilon(\widetilde{\sigma})>0$. Consider now the successor nodes $\sigma^{\prime \prime} \in \widetilde{\sigma}^{+}$for which $\Delta a\left(\sigma^{\prime \prime}\right)+\Delta \varepsilon\left(\sigma^{\prime \prime}\right)>0$. It is easy to see that if we continue this way we inductively define a subtree, called $\Gamma_{\widetilde{\sigma}}$. Recall that the subtree $\Gamma_{\widetilde{\sigma}}$ is tree with $\widetilde{\sigma}$ as root and which contains all sucessor nodes of

\footnotetext{
${ }^{23} \mathrm{~A}$ careful reading of the proof deriving non-vanishing Gaussian curvature reveals that the set $B_{\delta}(K)$ can be chosen as large as necessary.
} 
$\widetilde{\sigma}$. Multiplying with contingent prices $p\left(\sigma^{\prime}\right)$ and summing over $\sigma^{\prime} \in \sigma^{+} \cap \Gamma_{\widetilde{\sigma}}$ gives

$$
\sum_{\sigma^{\prime} \in \sigma^{+} \cap \Gamma_{\tilde{\sigma}}} p\left(\sigma^{\prime}\right) \cdot\left[\Delta a\left(\sigma^{\prime}\right)+\Delta \varepsilon\left(\sigma^{\prime}\right)\right]=\sum_{\sigma^{\prime} \in \sigma^{+} \cap \Gamma_{\tilde{\sigma}}} p\left(\sigma^{\prime}\right) \cdot\left[\Delta c^{o}\left(\sigma^{\prime}\right)-\Delta f(k(\sigma), \theta)\right] .
$$

Using now the non-vanishing Gaussian curvature condition for preferences and the lemma above for production functions, we get $^{24}$

$$
\begin{gathered}
\sum_{\sigma^{\prime} \in \sigma^{+} \cap \Gamma_{\tilde{\sigma}}} p\left(\sigma^{\prime}\right) \cdot\left[\Delta c^{o}\left(\sigma^{\prime}\right)-\Delta f(k(\sigma), \theta)\right] \geq \\
-\delta_{1}(\sigma)+\underline{\rho} \frac{\left(\delta_{1}(\sigma)\right)^{2}}{p(\sigma)}+p(\sigma) \cdot \Delta \varepsilon(\sigma)+c \cdot \frac{(p(\sigma) \cdot \Delta \varepsilon(\sigma))^{2}}{p(\sigma)},
\end{gathered}
$$

where $\delta_{1}(\sigma)$ is defined as above.

Replacing $\Delta c^{o}\left(\sigma^{\prime}\right)-\Delta f(k(\sigma), \theta)$ by $\Delta a\left(\sigma^{\prime}\right)+\Delta \varepsilon\left(\sigma^{\prime}\right)$ gives

$$
\begin{gathered}
\sum_{\sigma^{\prime} \in \sigma^{+} \cap \Gamma_{\tilde{\sigma}}} p\left(\sigma^{\prime}\right) \cdot\left[\Delta a\left(\sigma^{\prime}\right)+\Delta \varepsilon\left(\sigma^{\prime}\right)\right] \\
\geq-\delta_{1}(\sigma)+\underline{\rho} \frac{\left(\delta_{1}(\sigma)\right)^{2}}{p(\sigma)}+p(\sigma) \cdot \Delta \varepsilon(\sigma) \\
+c \cdot \frac{(p(\sigma) \cdot \Delta \varepsilon(\sigma))^{2}}{p(\sigma)} .
\end{gathered}
$$

Similar to Chattopadhyay and Gottardi (1999), we define a function $\lambda: \Gamma \rightarrow[0,1]$ by

$$
\lambda\left(\sigma^{\prime}\right)=\frac{p\left(\sigma^{\prime}\right) \cdot\left[\Delta a\left(\sigma^{\prime}\right)+\Delta \varepsilon\left(\sigma^{\prime}\right)\right]}{\sum_{\sigma^{\prime} \in \sigma^{+} \cap \Gamma_{\tilde{\sigma}}} p\left(\sigma^{\prime}\right) \cdot\left[\Delta a\left(\sigma^{\prime}\right)+\Delta \varepsilon\left(\sigma^{\prime}\right)\right]} .
$$

when $\sigma^{\prime} \in \Gamma_{\widetilde{\sigma}}$, and by

$$
\lambda(\sigma)=1 \text { for } \sigma \in \widetilde{\sigma}^{-}, \lambda(\sigma)=0 \text { elsewhere }
$$

By construction of $\lambda$, it satisfies $\sum_{\sigma^{\prime} \in \sigma^{+} \cap \Gamma_{\tilde{\sigma}}} \lambda\left(\sigma^{\prime}\right)=1$. Furthermore, it has all the properties in the definition of a transfer pattern.

Now we consider an arbitrary path $\sigma^{\infty}$ in the subtree $\Gamma_{\widetilde{\sigma}}$. Define $\gamma=\min \{c, \underline{\rho}\}$. Equation (10) can then be written as

$$
\frac{1}{\lambda\left(\sigma^{\prime}\right)} \cdot p\left(\sigma^{\prime}\right) \cdot\left[\Delta a\left(\sigma^{\prime}\right)+\Delta \varepsilon\left(\sigma^{\prime}\right)\right] \geq
$$

\footnotetext{
${ }^{24}$ Note that the inequality in (9) holds if we sum the left-hand side over $\sigma^{+}$and therefore also holds by summing over the strictly positive terms, what is done in (9).
} 


$$
p(\sigma) \cdot \Delta a(\sigma)+\gamma \frac{(p(\sigma) \cdot \Delta a(\sigma))^{2}}{p(\sigma)}+p(\sigma) \cdot \Delta \varepsilon(\sigma)+\gamma \frac{(p(\sigma) \cdot \Delta \varepsilon(\sigma))^{2}}{p(\sigma)} .
$$

Inverting both sides of this equation we obtain

$$
\begin{gathered}
\frac{\lambda\left(\sigma^{\prime}\right)}{p\left(\sigma^{\prime}\right) \cdot\left[\Delta a\left(\sigma^{\prime}\right)+\Delta \varepsilon\left(\sigma^{\prime}\right)\right]} \leq \\
\frac{1}{p(\sigma) \cdot \Delta a(\sigma)+\gamma \frac{(p(\sigma) \cdot \Delta a(\sigma))^{2}}{p(\sigma)}+p(\sigma) \cdot \Delta \varepsilon(\sigma)+\gamma \frac{(p(\sigma) \cdot \Delta \varepsilon(\sigma))^{2}}{p(\sigma)}}
\end{gathered}
$$

for all $\sigma \in \Gamma_{\widetilde{\sigma}}$.

This is equivalent to

$$
\frac{\lambda\left(\sigma^{\prime}\right)}{p\left(\sigma^{\prime}\right) \cdot\left[\Delta a\left(\sigma^{\prime}\right)+\Delta \varepsilon\left(\sigma^{\prime}\right)\right]} \leq
$$

$$
\begin{aligned}
& \frac{1}{p(\sigma) \cdot[\Delta a(\sigma)+\Delta \varepsilon(\sigma)]} \\
& \cdot\left(1-\frac{\frac{\gamma}{p(\sigma)} \cdot\left[(p(\sigma) \cdot \Delta a(\sigma))^{2}+(p(\sigma) \cdot \Delta \varepsilon(\sigma))^{2}\right]}{p(\sigma) \cdot \Delta a(\sigma)+\gamma \frac{(p(\sigma) \cdot \Delta a(\sigma))^{2}}{p(\sigma)}+p(\sigma) \cdot \Delta \varepsilon(\sigma)+\gamma \frac{(p(\sigma) \cdot \Delta \varepsilon(\sigma))^{2}}{p(\sigma)}}\right) .
\end{aligned}
$$

Further algebraic manipulations on the right-hand side give

$$
\begin{gathered}
\frac{\lambda\left(\sigma^{\prime}\right)}{p\left(\sigma^{\prime}\right) \cdot\left[\Delta a\left(\sigma^{\prime}\right)+\Delta \varepsilon\left(\sigma^{\prime}\right)\right]} \leq \\
\frac{1}{p(\sigma) \cdot[\Delta a(\sigma)+\Delta \varepsilon(\sigma)]} \\
-\frac{1}{\frac{\gamma}{\left.\left.\frac{\gamma}{p(\sigma)} \cdot\left[(p(\sigma) \cdot \Delta a(\sigma) \cdot \Delta a(\sigma))^{2}+(p \varepsilon(\sigma)]\right)^{2} \cdot \Delta \varepsilon(\sigma)\right)^{2}\right]}+p(\sigma) \cdot[\Delta a(\sigma)+\Delta \varepsilon(\sigma)]}
\end{gathered}
$$

so that we finally obtain

$$
\begin{gathered}
\frac{\lambda\left(\sigma^{\prime}\right)}{p\left(\sigma^{\prime}\right) \cdot\left[\Delta a\left(\sigma^{\prime}\right)+\Delta \varepsilon\left(\sigma^{\prime}\right)\right]} \leq \\
\frac{1}{p(\sigma) \cdot[\Delta a(\sigma)+\Delta \varepsilon(\sigma)]}-\frac{\gamma}{p(\sigma)} \frac{1}{\frac{[\Delta a(\sigma)+\Delta \varepsilon(\sigma)]^{2}}{(\Delta a(\sigma))^{2}+(\Delta \varepsilon(\sigma))^{2}}+\Delta a(\sigma)+\Delta \varepsilon(\sigma)}
\end{gathered}
$$

We want to show next that the expression $\frac{[\Delta a(\sigma)+\Delta \varepsilon(\sigma)]^{2}}{(\Delta a(\sigma))^{2}+(\Delta \varepsilon(\sigma))^{2}}+\Delta a(\sigma)+\Delta \varepsilon(\sigma)$, which by the assumptions made on the subtree $\Gamma_{\widetilde{\sigma}}$ is strictly positive, is also bounded above. By 
the resource constraint and the assumption that the economy is bounded, $\Delta a(\sigma)+\Delta \varepsilon(\sigma)$ is clearly bounded above. Rewrite $\frac{[\Delta a(\sigma)+\Delta \varepsilon(\sigma)]^{2}}{(\Delta a(\sigma))^{2}+(\Delta \varepsilon(\sigma))^{2}}$ as

$$
\frac{(\Delta a(\sigma))^{2}}{(\Delta a(\sigma))^{2}+(\Delta \varepsilon(\sigma))^{2}}+\frac{2 \Delta a(\sigma) \Delta \varepsilon(\sigma)}{(\Delta a(\sigma))^{2}+(\Delta \varepsilon(\sigma))^{2}}+\frac{(\Delta \varepsilon(\sigma))^{2}}{(\Delta a(\sigma))^{2}+(\Delta \varepsilon(\sigma))^{2}}
$$

The first and the third term are bounded above by 1 and so is the middle term because

$$
\frac{2 \Delta a(\sigma) \Delta \varepsilon(\sigma)}{(\Delta a(\sigma))^{2}+(\Delta \varepsilon(\sigma))^{2}}=\frac{2}{\frac{\Delta a(\sigma)}{\Delta \varepsilon(\sigma)}+\frac{\Delta \varepsilon(\sigma)}{\Delta a(\sigma)}}
$$

and the function $x+1 / x$ is bounded below by 2 on the positive real line.

So there is a constant $K>0$ such that $\frac{[\Delta a(\sigma)+\Delta \varepsilon(\sigma)]^{2}}{(\Delta a(\sigma))^{2}+(\Delta \varepsilon(\sigma))^{2}}+\Delta a(\sigma)+\Delta \varepsilon(\sigma) \leq K$. Inserting this into (16) gives

$$
\frac{\lambda\left(\sigma^{\prime}\right)}{p\left(\sigma^{\prime}\right) \cdot\left[\Delta a\left(\sigma^{\prime}\right)+\Delta \varepsilon\left(\sigma^{\prime}\right)\right]} \leq \frac{1}{p(\sigma) \cdot[\Delta a(\sigma)+\Delta \varepsilon(\sigma)]}-\frac{\gamma}{p(\sigma)} \frac{1}{K}
$$

If we now iterate this inequality along $\sigma^{\infty}$ starting with $\widetilde{\sigma}$, we obtain

$$
\begin{aligned}
& \frac{\lambda\left(\sigma_{T}^{\infty}\right) \ldots \lambda\left(\sigma_{t(\widetilde{\sigma})}^{\infty}\right)}{p\left(\sigma_{T}^{\infty}\right) \cdot\left[\Delta a\left(\sigma_{T}^{\infty} ; \sigma_{T}^{\infty}\right)+\Delta \varepsilon\left(\sigma_{T}^{\infty}\right)\right]}+\frac{\gamma}{K} \sum_{t=t(\widetilde{\sigma})}^{T-1} \frac{\lambda\left(\sigma_{t}^{\infty}\right) \cdot \ldots \cdot \lambda\left(\sigma_{t(\widetilde{\sigma})}^{\infty}\right)}{p\left(\sigma_{t}^{\infty}\right)} \\
& \leq \frac{1}{p(\widetilde{\sigma}) \cdot[\Delta a(\widetilde{\sigma})+\Delta \varepsilon(\widetilde{\sigma})]},
\end{aligned}
$$

So that $\lim _{T \rightarrow \infty} \sum_{t=t(\widetilde{\sigma})}^{T-1} \frac{\lambda\left(\sigma_{t}^{\infty}\right) \cdot \ldots \cdot \lambda\left(\sigma_{t(\tilde{\sigma})}^{\infty}\right)}{p\left(\sigma_{t}^{\infty}\right)}$ as being increasing in $T$ must converge to a positive real number, call it $A^{\prime}$. Note that with the normalization $p\left(\sigma_{0}\right)=1$ we have $p\left(\sigma_{t}^{\infty}\right)=$ $\prod_{s=1}^{t} \frac{1}{m r s\left(\sigma_{s}^{\infty}, \sigma_{s-1}^{\infty}\right)}$. Given our definition of the transfer pattern $\lambda$, this implies the existence of a positive real number $A$ such that in the case when an interim Pareto improvement is possible, (5) would hold. This completes the proof.

\section{Proposition 6}

\section{Proof.}

1. see 3 .

2. see 3 .

3. For notational simplicity the proof of the first claim will be given for two period 
bonds. The result immediately generalizes as shown below. Assume without loss of generality that the series $\sum_{t=0}^{\infty} \prod_{s=0}^{t} R_{2}\left(\sigma_{2 s}^{\infty}\right)$ converges uniformly along all paths $\sigma^{\infty}$. For odd $t$ define now $\lambda\left(\sigma_{t}^{\infty}\right)=\frac{\sum_{\sigma^{\prime} \in\left(\sigma_{t}^{\infty}\right)^{+}} p\left(\sigma^{\prime}\right)}{\sum_{\tilde{\sigma} \in\left(\sigma_{t-1}^{\infty}\right)^{++}} p(\widetilde{\sigma})}$, and for even $t$ we define $\lambda\left(\sigma_{t}^{\infty}\right)=$ $\frac{p\left(\sigma_{t}^{\infty}\right)}{\sum_{\sigma^{\prime} \in\left(\sigma_{t-1}^{\infty}\right)}+p\left(\sigma^{\prime}\right)}$. Note that now

$$
\lambda\left(\sigma_{2 t-1}^{\infty}\right) \cdot \lambda\left(\sigma_{2 t}^{\infty}\right)=\frac{p\left(\sigma_{2 t}^{\infty}\right)}{\sum_{\widetilde{\sigma} \in\left(\sigma_{2 t-2}^{\infty}\right)^{++}} p(\widetilde{\sigma})} .
$$

Consider

$$
\begin{gathered}
\frac{\prod_{i=1}^{2 t} \lambda\left(\sigma_{i}^{\infty}\right)}{p\left(\sigma_{2 t}^{\infty}\right)}=\frac{1}{p\left(\sigma_{2 t}^{\infty}\right)} \cdot \frac{p\left(\sigma_{2}^{\infty}\right)}{\sum_{\widetilde{\sigma} \in\left(\sigma_{0}^{\infty}\right)^{++}} p(\widetilde{\sigma})} \cdot \ldots \cdot \frac{p\left(\sigma_{2 t}^{\infty}\right)}{\left.\sum_{\widetilde{\sigma} \in\left(\sigma_{2 t-2}^{\infty}\right)}\right)^{++} p(\widetilde{\sigma})} \\
=\frac{p\left(\sigma_{2 t-2}^{\infty}\right)}{\sum_{\widetilde{\sigma} \in\left(\sigma_{2 t-2}^{\infty}\right)^{++}} p(\widetilde{\sigma})} \cdot \ldots \cdot \frac{p\left(\sigma_{0}^{\infty}\right)}{\sum_{\widetilde{\sigma} \in\left(\sigma_{0}^{\infty}\right)^{++}} p(\widetilde{\sigma})} \\
=\prod_{s=0}^{t-1} R_{2}\left(\sigma_{2 s}\right)
\end{gathered}
$$

If we consider now $\frac{\prod_{i=1}^{2 t} \lambda\left(\sigma_{i}^{\infty}\right)}{p\left(\sigma_{2 t}^{\infty}\right)}$ and define $\lambda\left(\sigma_{2 t+1}^{\infty}\right)$ arbitrary between 0 and 1 and all others $\lambda$ as above, we get

$$
\begin{gathered}
\frac{\prod_{i=1}^{2 t+1} \lambda\left(\sigma_{i}^{\infty}\right)}{p\left(\sigma_{2 t+1}^{\infty}\right)}=\frac{1}{p\left(\sigma_{2 t+1}^{\infty}\right)} \cdot \frac{p\left(\sigma_{2}^{\infty}\right)}{\sum_{\widetilde{\sigma} \in\left(\sigma_{0}^{\infty}\right)^{++}} p(\widetilde{\sigma})} \cdot \ldots \cdot \frac{p\left(\sigma_{2 t}^{\infty}\right)}{\sum_{\widetilde{\sigma} \in\left(\sigma_{2 t-2}^{\infty}\right)^{++}} p(\widetilde{\sigma})} \cdot \lambda\left(\sigma_{2 t+1}^{\infty}\right) \\
=\frac{p\left(\sigma_{2 t}^{\infty}\right) \cdot \lambda\left(\sigma_{2 t+1}^{\infty}\right)}{p\left(\sigma_{2 t+1}^{\infty}\right)} \cdot \prod_{s=0}^{t-1} R_{2}\left(\sigma_{2 s}\right) .
\end{gathered}
$$

Since by interiority of the competitive allocation the price ratio $\frac{p\left(\sigma_{2 t}^{\infty}\right)}{p\left(\sigma_{2 t+1}^{\infty}\right)}$ is bounded and $\lambda\left(\sigma_{2 t+1}^{\infty}\right) \leq 1$, the convergence condition in the main theorem holds for this choice of $\lambda$ if and only if the series with two period bond interest rates converges.

The condition for n-period bonds can be derived similarly. For $t=k \cdot n+m$ with $0 \leq m<n$ and $k \in \mathbb{N}$ we have for the right choice of $\lambda$

$$
\frac{\prod_{i=1}^{t} \lambda\left(\sigma_{i}^{\infty}\right)}{p\left(\sigma_{t}^{\infty}\right)}=\frac{p\left(\sigma_{k n}^{\infty}\right)}{p\left(\sigma_{k \cdot n+m}^{\infty}\right)} \cdot \prod_{i=1}^{m} \lambda\left(\sigma_{k n+i-1}^{\infty}\right) \cdot \prod_{j=0}^{k-1} R_{n}\left(\sigma_{j n}^{\infty}\right) .
$$


By the same argument as above convergence in the main theorem holds if and only if the corresponding series for $n$-period bonds converges.

4. For the last claim suppose the certain interest rate is larger than 1 everywhere. For any subtree $\Gamma_{\widehat{\sigma}}$ and any system of weight functions $\lambda_{\Gamma_{\widehat{\sigma}}}$ defined on it we have for any node $\sigma \in \Gamma_{\widehat{\sigma}}$ and for some $\sigma^{\prime} \in \sigma_{n}^{+} \cap \Gamma_{\widehat{\sigma}}$ that $\lambda_{n \Gamma_{\widehat{\sigma}}}\left(\sigma^{\prime}\right) \cdot p(\sigma) \geq p\left(\sigma^{\prime}\right)$ where $\lambda_{n}$ is the $n$-fold product of the transfer pattern $\lambda_{\Gamma_{\widehat{\sigma}}}$ defined on $\Gamma_{\widehat{\sigma}}$. This is so because otherwise $p(\sigma)=\sum_{\sigma^{\prime} \in \sigma_{n}^{+} \cap \Gamma_{\widehat{\sigma}}} \lambda_{\Gamma_{\widehat{\sigma}}}\left(\sigma^{\prime}\right) \cdot p(\sigma)<\sum_{\sigma^{\prime} \in \sigma_{n}^{+} \cap \Gamma_{\widehat{\sigma}}} p\left(\sigma^{\prime}\right) \leq \sum_{\sigma^{\prime} \in \sigma_{n}^{+}} p\left(\sigma^{\prime}\right)$, which contradicts the assumption on $R_{n}(\sigma)$. But this implies the existence of a path $\sigma^{\infty} \in \Gamma_{\widehat{\sigma}}$ for which $\sum_{t=t(\widehat{\sigma})}^{\infty} \frac{\prod_{s=1}^{t} \lambda_{\Gamma_{\widehat{\sigma}}}\left(\sigma_{s}^{\infty}\right)}{p\left(\sigma_{t}^{\infty}\right)}$ diverges, because $\lambda_{n \Gamma_{\widehat{\sigma}}}\left(\sigma^{\prime}\right) \cdot p(\sigma) \geq p\left(\sigma^{\prime}\right) \Longleftrightarrow$ $\frac{1}{p(\sigma)} \leq \frac{\lambda_{n \Gamma_{\widehat{\sigma}}}\left(\sigma^{\prime}\right)}{p\left(\sigma^{\prime}\right)}$

5. For all $\sigma_{t}^{\infty}$ define $\lambda\left(\sigma_{t}^{\infty}\right)=\frac{\sum_{\sigma^{\prime} \in\left(\sigma_{t}^{\infty}\right)^{+}} p\left(\sigma^{\prime}\right)}{\sum_{\tilde{\sigma} \in\left(\sigma_{t-1}^{\infty}\right)^{++}} p(\widetilde{\sigma})}$. With this transfer pattern, we have

$$
\begin{gathered}
\frac{\prod_{i=1}^{t} \lambda\left(\sigma_{i}^{\infty}\right)}{p\left(\sigma_{t}^{\infty}\right)}=\frac{\sum_{\sigma^{\prime} \in\left(\sigma_{t}^{\infty}\right)^{+}} p\left(\sigma^{\prime}\right)}{p\left(\sigma_{t}^{\infty}\right)} \cdot \frac{p\left(\sigma_{t-1}^{\infty}\right)}{\sum_{\widetilde{\sigma} \in\left(\sigma_{t-1}^{\infty}\right)^{++}} p(\widetilde{\sigma})} \cdot \frac{\sum_{\sigma^{\prime} \in\left(\sigma_{t-1}^{\infty}\right)^{+}} p\left(\sigma^{\prime}\right)}{p\left(\sigma_{t-1}^{\infty}\right)} \cdot \ldots \cdot \frac{1}{\sum_{\widetilde{\sigma} \in\left(\sigma_{0}^{\infty}\right)^{++}} p(\widetilde{\sigma})} \\
=\prod_{i=1}^{t} \frac{R_{2}\left(\sigma_{i-1}^{\infty}\right)}{R_{1}\left(\sigma_{i}^{\infty}\right)}
\end{gathered}
$$

where for the first equality we use the normalization $p\left(\sigma_{0}^{\infty}\right)=1$.

So with this transfer pattern, the convergence in the condition of the main theorem occurs if and only if $\sum_{t=1}^{\infty} \prod_{i=1}^{t} \frac{R_{2}\left(\sigma_{i-1}^{\infty}\right)}{R_{1}\left(\sigma_{i}^{\infty}\right)}$ is uniformly bounded for every path $\sigma^{\infty}$. This proves the last claim.

\section{Remark 13}

Proof. In the following example we construct a generic competitive equilibrium allocation that is dynamically efficient without being intertemporal exchange efficient or interim Pareto optimal respectively. Consider an economy with two possible shocks each period of time. Let $\left(\alpha_{i}\right)_{i=0}^{\infty}$ be a sequence of real numbers $0<\alpha_{i}<1$ with the property $\prod_{i=0}^{\infty} \alpha_{i}>0$, which is equivalent to $\sum_{i=0}^{\infty}\left(1-\alpha_{i}\right)<\infty$. Suppose there is a sequence of shocks $\left(\theta_{t}\right)_{t=0}^{\infty}$ with $\theta_{t} \in A_{t}$ for all $t$ such that $\alpha_{i}=q_{i}\left(\theta_{i} \mid \theta_{i-1}, \ldots, \theta_{0}\right)$. In other words, there exists a path in the tree which has strictly positive probability. Suppose further that along 
the path $\sigma^{\infty}=\left(\theta_{0}, \theta_{1}, \ldots\right)$ we have $\psi\left(\sigma_{i}\right)=3^{i}$ and hence $\sum_{i=0}^{\infty} 1 / \psi\left(\sigma_{i}\right)<\infty$. Assume furthermore that for every node $\sigma$ in the tree there exists a path $\widetilde{\sigma}^{\infty}$ with $\sigma \in \widetilde{\sigma}^{\infty}$ such that $\sum_{i=0}^{\infty} 1 / \psi\left(\widetilde{\sigma}_{i}\right)=\infty$.

Clearly the economy described above is not dynamically inefficient although the series $\sum_{i=0}^{\infty} \frac{1}{\psi\left(\sigma_{i}\right)}$ converges (and is therefore in this case uniformly bounded) on a set of strictly positive measure, since there is no node in the tree at which a dissaving is possible without a later decrease in consumption.

However, an interim Pareto-improving pure redistribution is possible. We have $\prod_{i=0}^{t} \alpha_{i}$. $\psi\left(\sigma_{t}\right) \geq\left(\prod_{i=0}^{T} \alpha_{i}\right) \cdot(1-\varepsilon)^{t-T} \cdot \psi\left(\sigma_{t}\right)$ for every $\varepsilon>0$ and some $T$ when $t>T$. Since for an $\varepsilon$ sufficiently small we have $\sum_{t=T+1}^{\infty} \frac{\frac{1}{(1-\varepsilon)^{t-T}}}{\psi\left(\sigma_{t}\right)}=\sum_{t=T+1}^{\infty} \frac{\frac{1}{(1-\varepsilon)^{t-T}}}{3^{t}}<\infty$, the claim follows immediately by choosing the degenerate subtree consisting of the path $\sigma^{\infty}$ and by applying theorem 5 .

To make the example more concrete, suppose that preferences of the consumers along the convergent path $\sigma^{\infty}$ are of the form $u_{\sigma_{t}}(c(\sigma))=\ln c^{y}(\sigma)+b\left(\sigma_{t}\right) \cdot \alpha_{t} \ln c^{o}\left(\sigma_{1}^{\prime}\right)+b\left(\sigma_{t}\right)$. $\left(1-\alpha_{t}\right) \ln c^{o}\left(\sigma_{2}^{\prime}\right)$, where $b\left(\sigma_{t}\right)$ is a positive real number. Let the technology be given by

$$
f(k, \theta)=a(\theta) \cdot k^{\beta},
$$

where $\beta$ will be chosen to satisfy a certain condition and $0<\beta<1$.

Suppose the individual born in $\sigma_{t}$ faces given interest rates of 3 and $\frac{1}{3}$ in the two possible events in his second period of life. The individual's problem is then

$$
\begin{aligned}
& \max \quad \ln c^{y}\left(\sigma_{t}\right)+b \cdot \alpha_{t} \ln c^{o}\left(\sigma_{1}^{\prime}\right)+b \cdot\left(1-\alpha_{t}\right) \ln c^{o}\left(\sigma_{2}^{\prime}\right) \\
& \text { s.t. } \quad c^{y}\left(\sigma_{t}\right)+s\left(\sigma_{t}\right)=w\left(\sigma_{t}\right) \\
& c^{o}\left(\sigma_{1}^{\prime}\right)=\frac{1}{3} \cdot s\left(\sigma_{t}\right) \\
& c^{o}\left(\sigma_{2}^{\prime}\right)=3 \cdot s\left(\sigma_{t}\right)
\end{aligned}
$$

It follows that $s\left(\sigma_{t}\right)=g \cdot w\left(\sigma_{t}\right)$, where we define $g=\frac{b}{1+b}$. Given the savings decision $s\left(\sigma_{t}\right)$, in order for 3 and $\frac{1}{3}$ to be equilibrium interest rates we must have

$$
f^{\prime}\left(s\left(\sigma_{t}\right), \theta_{1}\right)=a\left(\theta_{1}\right) \cdot \beta \cdot\left(s\left(\sigma_{t}\right)\right)^{\beta-1}=\frac{1}{3},
$$




$$
f^{\prime}\left(s\left(\sigma_{t}\right), \theta_{2}\right)=a\left(\theta_{2}\right) \cdot \beta \cdot\left(s\left(\sigma_{t}\right)\right)^{\beta-1}=3 .
$$

We know $w\left(\sigma_{t}\right)=(1-\beta) \cdot a(\theta) \cdot\left(k\left(\sigma_{t-1}\right)\right)^{\beta}$ where $\sigma_{t}=\left(\theta, \sigma_{t-1}\right)$. Thus,

$$
s\left(\sigma_{t}\right)=g\left(\sigma_{t}\right) \cdot(1-\beta) \cdot a(\theta) \cdot\left(k\left(\sigma_{t-1}\right)\right)^{\beta} .
$$

The function $f(x)=g \cdot(1-\beta) \cdot a(\theta) \cdot x^{\beta}$ has for fixed $a(\theta)$ a nonzero fixed point, which we call $k^{*}$. We can now solve, for an arbitrary given $k^{*}$, for the corresponding $a$, which is given by $a=\left[\frac{1}{g} \cdot(1-\beta)\right] \cdot\left(k^{*}\right)^{1-\beta}$. Plugging $k^{*}$ for $s\left(\sigma_{t}\right)$ and $\left[\frac{1}{g} \cdot(1-\beta)\right] \cdot\left(k^{*}\right)^{1-\beta}$ for $a\left(\theta_{1}\right)$ into $(22), k^{*}$ cancels out and the resulting condition for $\beta$ is

$$
\frac{1}{g} \cdot \frac{\beta}{1-\beta}=\frac{1}{3}
$$

or equivalently

$$
\beta=\frac{\frac{1}{3} \cdot g}{1+\frac{1}{3} \cdot g}
$$

If we choose $a\left(\theta_{2}\right)=9 \cdot a\left(\theta_{1}\right)$, the second equation above is also satisfied.

Up to now we have constructed a $k^{*}$, so that a capital stock of $k^{*}$ is maintained if along the path $\sigma^{\infty}$ the same shock always occurs. It is clear from our construction that once we deviate from this path, agents have a higher wage income. Hence, since $g$ remains fixed, households save more. Hence, if the same shocks occur each period, higher capital stock means higher wages and therefore higher savings etc. Thus the capital stock off the path will never fall below $k^{*}$. Furthermore, by $a\left(\theta_{2}\right) \cdot k^{\beta}=k \Longleftrightarrow k=a\left(\theta_{2}\right)^{\frac{1}{1-\beta}}$, an upper bound on the maximal possible capital stock is given. Since $a\left(\theta_{1}\right)$ and therefore $a\left(\theta_{2}\right)$ depend on the choice of $k^{*}$ as described above, $k^{*}$ can be chosen sufficiently large to ensure $a\left(\theta_{2}\right) \cdot \beta \cdot a\left(\theta_{2}\right)^{\frac{\beta}{1-\beta}}$, the lowest possible interest rate when the "high" shock $a\left(\theta_{2}\right)$ occurs, to be strictly larger than 1 . Given this lower bound on interest rates for "good states", the economy is dynamically efficient. We fix the probabilities of shocks off the path equal to $(1 / 2,1 / 2)$.

Overall, the examples display all the features described in the first few paragraphs of this section. Furthermore, all assumptions made in our main theorem are satisfied: capital stock is bounded away from zero, because of the fixed saving rate and the boundedness of capital stock, also consumption is bounded away from zero. 


\section{E Proposition 8}

Proof. Let $\left(c^{*}, k^{*}\right)$ be a given interior short run optimal allocation. Short run optimality implies (by the second welfare theorem for finite economies) that for each consumer $\sigma$, $k^{*}(\sigma)$ is a solution to the following problem

$$
\begin{gathered}
\max _{s(\sigma)} E_{\sigma} u(c(\sigma)) \\
\text { s.t. } \quad c^{y}(\sigma)+s(\sigma) \leq w(\sigma)+\widetilde{T}(\sigma) \\
c^{o}\left(\sigma^{\prime}\right) \leq f(s(\sigma), \theta)+\widetilde{T}\left(\sigma^{\prime} ; \sigma\right)
\end{gathered}
$$

for some transfers $\widetilde{T}$. It now follows from the first order conditions of this problem that it is then also a solution to

$$
\begin{gathered}
\max _{s(\sigma)} E_{\sigma} u(c(\sigma)) \\
\text { s.t. } \quad c^{y}(\sigma)+s(\sigma) \leq w^{*}(\sigma)+T^{* y}(\sigma) \\
c^{o}\left(\sigma^{\prime}\right) \leq r^{*}\left(\sigma^{\prime}\right) \cdot s(\sigma)+T^{* o}\left(\sigma^{\prime}\right), \quad \forall \sigma^{\prime} \in \sigma^{+}
\end{gathered}
$$

for appropriate transfers $T^{*}$ if $r^{*}\left(\sigma^{\prime}\right)=f^{\prime}\left(k^{*}(\sigma), \theta\right)$. Therefore every short run optimal interior allocation can be supported.

\section{F Remark 9}

We will show the equivalence of transfers and government debt. By the second welfare theorem, every competitive allocation can be implemented using appropriate transfers $T^{y}(\sigma)$ and $T^{o}\left(\sigma^{\prime}\right)$. We will show how the competitive allocation with these transfers can be implemented in an Arrow-Debreu equilibrium with government debt.

Given the allocation associated to the equilibrium with transfers $T$, there exist contingentclaims prices $p$ and transfers $\widetilde{T}$ such that the allocation is also the solution of the household 
problem in Arrow Debreu form

$$
\begin{array}{r}
\max _{c(\sigma), c\left(\sigma^{\prime}\right)} E_{\sigma} u\left(c(\sigma), c\left(\sigma^{\prime}\right)\right) \\
\text { s.t. } \quad p(\sigma) \cdot c(\sigma)+\sum_{\sigma^{\prime} \in \sigma^{+}} p\left(\sigma^{\prime}\right) \cdot c\left(\sigma^{\prime}\right)=w(\sigma)+\widetilde{T}(\sigma) .
\end{array}
$$

and the firm problem

$$
\max _{k(\sigma) \geq 0} \sum_{\sigma^{\prime} \in \sigma^{+}} p\left(\sigma^{\prime}\right) \cdot f(k(\sigma), \theta)-p(\sigma) \cdot k(\sigma)
$$

We will now show that $\widetilde{T}(\sigma)=p(\sigma) \cdot T^{y}(\sigma)+\sum_{\sigma^{\prime} \in \sigma^{+}} p\left(\sigma^{\prime}\right) \cdot T\left(\sigma^{\prime}\right)$.

The first order conditions for the Arrow Debreu problem are

$$
\begin{gathered}
E_{\sigma} u_{1}\left(c(\sigma), c\left(\sigma^{\prime}\right)\right)=\lambda \cdot p(\sigma) \\
q\left(\sigma^{\prime} \mid \sigma\right) \cdot u_{2}\left(c(\sigma), c\left(\sigma^{\prime}\right)\right)=\lambda \cdot p\left(\sigma^{\prime}\right) \quad \text { for all } \sigma^{\prime} \in \sigma^{+},
\end{gathered}
$$

where $\lambda>0$ is the Lagrange multiplier of the budget constraint.

The first order condition for the firm is

$$
\sum_{\sigma^{\prime} \in \sigma^{+}} \frac{p\left(\sigma^{\prime}\right)}{p(\sigma)} \cdot f^{\prime}(k(\sigma), \theta)=1
$$

If we consider the original saving problem with transfers

$$
\max _{\left(c^{y}(\sigma), s(\sigma),\left(c^{o}\left(\sigma^{\prime}\right)\right)_{\sigma^{\prime} \in \sigma^{+}}\right) \in \mathbb{R}_{+}^{2+S}} E_{\sigma} u(c(\sigma))
$$

$$
\text { s.t. } \begin{aligned}
c^{y}(\sigma)+s(\sigma) & =w(\sigma)+T^{y}(\sigma) \\
c^{o}\left(\sigma^{\prime}\right) & =r\left(\sigma^{\prime}\right) \cdot s(\sigma)+T^{o}\left(\sigma^{\prime}\right)
\end{aligned}
$$

where $E_{\sigma} u(c(\sigma)):=\sum_{\theta_{t+1 \in A}} q_{t+1}\left(\theta_{t+1} \mid \sigma\right) \cdot u\left(c^{y}(\sigma), x\left(\left(\sigma, \theta_{t+1}\right) ; \sigma\right)\right)$, the first order condition is

$$
\begin{gathered}
E_{\sigma} u_{1}\left(w(\sigma)+T^{y}(\sigma)-s(\sigma), r\left(\sigma^{\prime}\right) \cdot s(\sigma)+T^{o}\left(\sigma^{\prime}\right)\right)= \\
E_{\sigma}\left[u_{2}\left(w(\sigma)+T^{y}(\sigma)-s(\sigma), r\left(\sigma^{\prime}\right) \cdot s(\sigma)+T^{o}\left(\sigma^{\prime}\right)\right) \cdot r\left(\sigma^{\prime}\right)\right] .
\end{gathered}
$$


We note that $r\left(\sigma^{\prime}\right)=f^{\prime}(k(\sigma), \theta)$ and if we define $\frac{p\left(\sigma^{\prime}\right)}{p(\sigma)}=\frac{q\left(\sigma^{\prime} \mid \sigma\right) \cdot u_{2}\left(w(\sigma)+T^{y}(\sigma)-s(\sigma), r\left(\sigma^{\prime}\right) \cdot s(\sigma)+T^{o}\left(\sigma^{\prime}\right)\right)}{E_{\sigma} u_{1}\left(w(\sigma)+T^{y}(\sigma)-s(\sigma), r\left(\sigma^{\prime}\right) \cdot s(\sigma)+T^{o}\left(\sigma^{\prime}\right)\right)}$, the relative Arrow Debreu prices that support the Pareto optimal allocation, we see that the first order conditions of the Arrow Debreu problem will hold for an appropiate choice of $\lambda$. Furthermore,

$$
\begin{gathered}
p(\sigma) \cdot\left[w(\sigma)+T^{y}(\sigma)-s(\sigma)\right]+\sum_{\sigma^{\prime} \in \sigma^{+}} p\left(\sigma^{\prime}\right) \cdot\left(r\left(\sigma^{\prime}\right) \cdot s(\sigma)+T^{o}\left(\sigma^{\prime}\right)\right) \\
=p(\sigma) \cdot w(\sigma)+\underbrace{\left[-p(\sigma)+\sum_{\sigma^{\prime} \in \sigma^{+}} p\left(\sigma^{\prime}\right) \cdot r\left(\sigma^{\prime}\right)\right]}_{=0} \cdot s(\sigma)+p(\sigma) \cdot T^{y}(\sigma)+\sum_{\sigma^{\prime} \in \sigma^{+}} p\left(\sigma^{\prime}\right) \cdot T\left(\sigma^{\prime}\right) \\
=p(\sigma) \cdot w(\sigma)+\widetilde{T}(\sigma) .
\end{gathered}
$$

This shows that the Arrow Debreu formulation of the consumer problem with income $\widetilde{w}(\sigma)=p(\sigma) \cdot w(\sigma)+\widetilde{T}(\sigma)$ and relative contingent-claims prices equal to the marginal rates of substitution in the corresponding allocation has the same solution as the original saving problem.

Given the contingent-claims prices, the real returns for government debt, denoted $r^{m}(\sigma)$, have to satisfy the following arbitrage condition:

$$
p(\sigma)=\sum_{\sigma^{\prime} \in \sigma^{+}} r^{m}\left(\sigma^{\prime}\right) \cdot p\left(\sigma^{\prime}\right)
$$

We can now define the price for government bonds at node $\sigma_{t}^{\infty}$, denoted as $p^{m}\left(\sigma_{t}^{\infty}\right)$ as:

$$
p^{m}\left(\sigma_{t}^{\infty}\right)=\prod_{i=1}^{t} r^{m}\left(\sigma_{i}^{\infty}\right) \cdot p\left(\sigma_{t}^{\infty}\right) .
$$

With this definition, the following relation holds:

$$
p^{m}(\sigma)=\sum_{\sigma^{\prime} \in \sigma^{+}} p^{m}\left(\sigma^{\prime}\right)
$$

If the outstanding government debt at node $\sigma$ is denoted by $m(\sigma)$, the budget constraint of the consumer under a non-stationary debt policy becomes

$$
p(\sigma) \cdot c(\sigma)+\sum_{\sigma^{\prime} \in \sigma^{+}} p\left(\sigma^{\prime}\right) \cdot c\left(\sigma^{\prime}\right)=w(\sigma)-p^{m}(\sigma) \cdot m(\sigma)+\sum_{\sigma^{\prime} \in \sigma^{+}} p^{m}\left(\sigma^{\prime}\right) \cdot m\left(\sigma^{\prime}\right) .
$$


If now $m$ is chosen such that $\widetilde{T}(\sigma)=\sum_{\sigma^{\prime} \in \sigma^{+}} p^{m}\left(\sigma^{\prime}\right) \cdot m\left(\sigma^{\prime}\right)-p^{m}(\sigma) \cdot m(\sigma)$ for all nodes $\sigma$, the non-stationary government debt policy implements by the definition of $\widetilde{T}$ and $p$ the optimal allocation. In the case of a stationary debt policy (a debt Ponzi scheme), we have $m\left(\sigma^{\prime}\right)=m(\sigma)$ for all $\sigma^{\prime} \in \sigma^{+}$. Therefore, it follows $\widetilde{T}(\sigma)=0$.

Note that $T^{y}(\sigma)=-\frac{p^{m}(\sigma)}{p(\sigma)} \cdot m(\sigma)$. The transfers in old age are then given by $T^{o}\left(\sigma^{\prime}\right)=$ $r^{m}\left(\sigma^{\prime}\right) \cdot\left(-T^{y}(\sigma)\right)+\triangle T\left(\sigma^{\prime}\right)$, where $\triangle T\left(\sigma^{\prime}\right)$ is just difference between the return to government bonds and the transfer $T^{o}\left(\sigma^{\prime}\right)$. Thus $m\left(\sigma^{\prime}\right)=\frac{p\left(\sigma^{\prime}\right)}{p^{m}\left(\sigma^{\prime}\right)} \cdot T^{o}\left(\sigma^{\prime}\right)$. The last equations allow us to interpret the (negative) transfers in young age as the amount spend in government bonds. The transfer in old age is the return on the government bonds bought when young plus (or minus) an additional transfer or tax $\triangle T\left(\sigma^{\prime}\right)$.

\section{G Proposition 10}

Proof. The proof is an application of Zorn's lemma. By our assumption that the economy is bounded (end of section 2), we can w.l.o.g. assume that the total amount of the single commodity available at each node $\sigma$ is bounded above by some constant $\bar{y}$. Let $Y:=[0, \bar{y}]^{3}$ be the threefold product of the $[0, \bar{y}]$ interval. Define $\mathcal{Y}:=\prod_{\sigma \in \Gamma} Y$. By the Tychonoff Product Theorem $\mathcal{Y}$ is compact in the product topology. The set of feasible allocations, which we denote by $F$, is closed in the product topology and contained in $\mathcal{Y}$. Therefore it is also compact. Furthermore, by extending the utility functions in the canonical manner to $\mathcal{Y}$, they are continuous with respect to the product topology. Now let the feasible allocation $(c, k)$ be given.

Define a preorder $\succeq$ on $F$ by setting $(\widehat{c}, \widehat{k}) \succeq(\widetilde{c}, \widetilde{k}) \Longleftrightarrow \widehat{x}\left(\theta_{0},-1\right) \geq x\left(\theta_{0},-1\right)$ and $u_{\sigma}\left(\widehat{c}^{y}(\sigma),\left(\widehat{c}^{o}\left(\sigma^{\prime}\right)\right)_{\sigma^{\prime} \in \sigma^{+}}\right) \geq u_{\sigma}\left(c^{y}(\sigma),\left(c^{o}\left(\sigma^{\prime}\right)\right)_{\sigma^{\prime} \in \sigma^{+}}\right)$for all $\sigma \in \Gamma$.

Consider the set

$$
V_{(c, k)}:=\{(\widehat{c}, \widehat{k}) \in F \mid(\widehat{c}, \widehat{k}) \succeq(c, k)\}
$$

Clearly, $V_{(c, k)}$ is non-empty since it contains $(c, k)$. Furthermore, it is closed and therefore compact. Define

$\mathcal{V}:=\left\{V \subseteq V_{(c, k)} \mid V \neq \emptyset,(\widetilde{c}, \widetilde{k}) \in F\right.$ and $(\widetilde{c}, \widetilde{k}) \succeq(\widehat{c}, \widehat{k})$ for some $(\widehat{c}, \widehat{k}) \in V$ imply $\left.(\widetilde{c}, \widetilde{k}) \in V\right\}$ Maximal elements with respect to reverse set order on $\mathcal{V}$ are Pareto-optima and weakly preferred to $(c, k)$ in the preorder $\succeq$.

To show that maximal elements exist, it suffices by Zorn's lemma to show that every chain has an upper bound. Let $V_{\alpha}, \alpha \in \Lambda$ be a given chain, where $\Lambda$ is the index set. Consider the set $W:=\bigcap_{\alpha \in \Lambda} V_{\alpha}$. We have to show that this set is non-empty. Since the $V_{\alpha}$ sets are closed subsets of the compact space $\mathcal{Y}$, by the finite intersection property it 
suffices to show that any finite intersection of the $V_{\alpha}$ sets is non-empty. But this follows immediately from the fact that the $V_{\alpha}$ form a chain. We have $W \subseteq V_{\alpha}$ for all $\alpha \in \Lambda$ and therefore an upper bound for the chain. Thus by Zorn's lemma, there exists a maximal element $V^{*} \neq \emptyset$ in $\mathcal{V}$ with respect to $\subseteq$. All $\left(c^{*}, k^{*}\right) \in V^{*}$ are Pareto optimal allocations and satisfy $\left(c^{*}, k^{*}\right) \succeq(c, k)$.

\section{H Example AMSZ}

The example consists of consumers with logarithmic preferences and firms with CobbDouglas technology. There are two states of the world which correspond to different shocks to the production technology. Formally this means that production is given by $f\left(k, \omega_{i}\right) i=1,2$ with $f\left(k, \omega_{i}\right)=\omega_{i} \cdot k^{\alpha}, 0<\alpha<1, \omega_{1}=1$ and $\omega_{2}>1$, where $\omega_{1}$ and $\omega_{2}$ are the two shocks. The utility functions with parameter $a$ are given by:

$$
u=\ln c^{y}+a\left[p \ln c_{1}^{o}+(1-p) \ln c_{2}^{o}\right]
$$

where $p$ is the probability of shock $\omega_{1}$. We will construct a set of equilibria for this economy which all have three different risk-free interest rates, one larger than one and two of them smaller than one, which may appear in arbitrary order along each path, i.e. there are three numbers $R_{1}>1, R_{2}<1$ and $R_{3}<1$ such that at every node in the tree the risk-free interest rate may equal either $R_{1}, R_{2}$ or $R_{3}$. If $R_{2}$ and $R_{3}$ appear sufficiently often along each path, our sufficent condition for inefficiency will be met. On the other hand, if the high shock $\omega_{2}$ has occured, for any level of investment for the next period chosen, the net dividend criterion will be satisfied. In case of the low shock $\omega_{1}$, the low investment level which leads to $R_{1}$ has to be chosen if we want the net dividend criterion to hold. So if one observes a path with sufficiently many of the high shocks $\omega_{2}$, it may well be possible that the net dividend criterion will be satisfied along this path, but the overall economy is nevertheless inefficient.

Note first, tha the wage is given by $w\left(\omega_{i}, k\right)=(1-\alpha) \cdot \omega_{i} \cdot k^{\alpha}$. Given relative contingentclaims prices $q_{1}$ and $q_{2}$ the household solves

$$
\begin{gathered}
\max _{c^{y}, c_{1}^{o}, c_{2}^{o}} \ln c^{y}+a\left[p \ln c_{1}^{o}+(1-p) \ln c_{2}^{o}\right] \\
\text { s.t. } c^{y}+q_{1} c_{1}^{o}+q_{2} c_{2}^{o}=w .
\end{gathered}
$$


From the first order conditions we obtain

$$
\frac{a p}{q_{1}}=\frac{c_{1}^{o}}{c^{y}}
$$

and

$$
\frac{a(1-p)}{q_{2}}=\frac{c_{2}^{o}}{c^{y}}
$$

We can also consider the household problem if we formulate it as a saving problem:

$$
\begin{aligned}
& \max _{c^{y}, c_{1}^{o}, c_{2}^{o}, s} \ln c^{y}+a\left[p \ln c_{1}^{o}+(1-p) \ln c_{2}^{o}\right] \\
& \text { s.t. } \quad c^{y}+s=w \\
& r_{1} \cdot s=c_{1}^{o}, r_{2} \cdot s=c_{2}^{o},
\end{aligned}
$$

where $r_{i}$ is the return to investment in state $i$. The first order condition is now:

$$
\frac{1}{w-s}=p a \frac{1}{s}+(1-p) a \frac{1}{s}
$$

Solving for $s$ yields:

$$
s=\frac{a}{1+a} \cdot w .
$$

This gives $r_{1} \cdot \frac{a}{1+a} \cdot w=c_{1}^{o}, r_{2} \cdot \frac{a}{1+a} \cdot w=c_{2}^{o}$ and $c^{y}=\frac{1}{1+a} \cdot w$.

To obtain this solution in the first problem we have to set relative contingent-claims prices equal to

$$
q_{1}=\frac{p}{r_{1}}, q_{2}=\frac{1-p}{r_{2}} .
$$

Three different levels of capital stock shall occur in the equilibria we consider, $k_{1}, k_{2}, k_{3}$. Instead of working with the $k_{i}$, we consider instead $\widetilde{r}_{i}:=\alpha k_{i}^{\alpha-1}$. So let $\widetilde{r}_{1}, \widetilde{r}_{2}$ and $\widetilde{r}_{3}$ be given. The risky interest rate if contemporary capital stock is $k_{i}$ and current shock is $\omega_{j}$ is thus given by $r_{i j}:=\omega_{j} \cdot \widetilde{r}_{i}$. The risk-free interest rates $R_{i}$ are computed according to

$$
R_{i}=\frac{1}{q_{i 1}+q_{i 2}}
$$

with $q_{i 1}=\frac{p}{r_{i 1}}$ and $q_{i 2}=\frac{1-p}{r_{i 2}}$.

Let w.l.o.g. $\widetilde{r}_{1}>\widetilde{r}_{2}>\widetilde{r}_{3}$ (i.e. $k_{1}$ is the lowest capital stock etc.). First, the $\widetilde{r}_{i}$ have to be such that given the wage generated by the lowest capital stock $k_{1}$ and the low shock $\left(\omega_{1}\right)$ it is still possible that consumers with a certain parameter $a$ chose the highest capital 
stock $k_{3}$ as their savings. In this case consumers have the lowest possible wage and are supposed to choose the highest possible capital stock. Note that given the form of the savings function (23), it suffices to require that the wage resulting from $k_{1}$ and $\omega_{1}$ is larger than $k_{3}$. Expressed in terms of the $\widetilde{r}_{i}$ this amounts to

$$
\begin{aligned}
& (1-\alpha)\left(\frac{\widetilde{r}_{1}}{\alpha}\right)^{\frac{\alpha}{\alpha-1}} \geq\left(\frac{\widetilde{r}_{3}}{\alpha}\right)^{\frac{1}{\alpha-1}} \\
& \Longleftrightarrow\left(\frac{\alpha}{1-\alpha}\right)^{1-\alpha} \cdot \widetilde{r}_{1}^{\alpha} \leq \widetilde{r}_{3} .
\end{aligned}
$$

If the condition is satisfied for $\widetilde{r}_{1}$ and $\widetilde{r}_{3}$, then it necessarly also holds for all other combinations of capital stocks.

Now $R_{i}$ can be expressed in terms of the corresponding $\widetilde{r}_{i}$ :

$$
R_{i}=\frac{1}{\frac{p}{\widetilde{r}_{i}}+\frac{1-p}{\omega_{2} \widetilde{r}_{i}}}=\frac{\omega_{2}}{\omega_{2} p+(1-p)} \cdot \widetilde{r}_{i}
$$

We want to have that $R_{3}$ and $R_{2}$ are less than 1 and $R_{1}>1$. Since $\frac{\omega_{2}}{\omega_{2} p+(1-p)}>1$, we see that this necessarily requires $\widetilde{r}_{3}, \widetilde{r}_{2}<1$.

The criterion of AMSZ for efficiency, considered along a path in the framework of this example, requires that factor payments to capital are strictly larger than saving for the next period:

$$
\alpha \cdot \omega_{j} \cdot k_{i}^{\alpha}>k_{l}
$$

where the current capital stock is $k_{i}$, the current shock is $\omega_{j}$ and the next period's capital stock $k_{l}$. Expressed in terms of $\widetilde{r}_{i}$, this gives

$$
\begin{gathered}
\alpha \cdot \omega_{j} \cdot\left(\frac{\widetilde{r}_{i}}{\alpha}\right)^{\frac{\alpha}{\alpha-1}}>\left(\frac{\widetilde{r}_{l}}{\alpha}\right)^{\frac{1}{\alpha-1}} \\
\Longleftrightarrow \omega_{j}^{\alpha-1} \cdot \widetilde{r}_{i}^{\alpha}<\widetilde{r}_{l} .
\end{gathered}
$$

Again it suffices to require the inequality for $\widetilde{r}_{1}$ on the lhs and $\widetilde{r}_{3}$ on the rhs.

Note that for $\alpha=\frac{1}{3}$ and $\omega_{2}=2$, we have $\frac{1-\alpha}{\alpha}=\frac{\frac{2}{3}}{\frac{1}{3}}=2$, and thus conditions (26) and (24) coincide in this case. If we choose additionally $p=\frac{1}{2}$, we see from (25) that $R_{i}=2 \cdot \frac{2}{1+2} \cdot \widetilde{r}_{i}=\frac{4}{3} \cdot \widetilde{r}_{i}$.

Thus, we must have $\widetilde{r}_{3}, \widetilde{r}_{2}<\frac{3}{4}$. In order to show that in this case a $\widetilde{r}_{1}$ with $\widetilde{r}_{1}>\widetilde{r}_{2}>\widetilde{r}_{3}$ 
exists that satisfies (24) (and thus equivalently (26)), it suffices to check whether

$$
\frac{1}{2^{\frac{2}{3}}} \cdot \widetilde{r}_{1}^{\frac{1}{3}}<\frac{3}{4}
$$

has a solution $\widetilde{r}_{1}>1$. For $\omega_{1}=1$ the inequality (26) becomes $\widetilde{r}_{i}^{\alpha}<\widetilde{r}_{l}$ and will then be satisfied for $i=2,3$ and $l=1$. But the condition is equivalent to

$$
\widetilde{r}_{1}<\left(\frac{3}{4}\right)^{3} \cdot 4
$$

The last term is greater than 1 and thus the desired conclusion follows.

In general, one has to check whether given the parameters $\alpha, p$ and $\omega_{2}$, there exist $\widetilde{r}_{1}>1>\widetilde{r}_{2}>\widetilde{r}_{3}$ that satisfy the inequalities (24), (26) for $\omega_{2}$ and all possible indices, (26) for $\omega_{1}=1$ and for $i=2,3$ and $l=1$, and $R_{i}=\frac{\omega_{2}}{\omega_{2} p+(1-p)} \cdot \widetilde{r}_{i}<1, i=2,3, R_{1}=$ $\frac{\omega_{2}}{\omega_{2} p+(1-p)} \cdot \widetilde{r}_{1}>1$ simultaneously.

In this case one can construct economies with arbitrary risk-free interest rate sequences, in which the net-dividend criterion will be satisfied on all paths on which in case of the low shock $\omega_{1}$ the current capital stock is $k_{2}$ or $k_{3}$ and $k_{1}$ is chosen for the next period or the current capital stock is $k_{1}$ and $k_{1}$ is chosen for the next period.

Suppose we construct an equilibrium in which $R_{2}$ and $R_{3}$ appear sufficiently often to make the economy interim Pareto suboptimal. If we observe a path which contains many more $\omega_{2}$ than $\omega_{1}$ shocks, then the preceding results imply that the frequent appearance of $R_{2}$ and $R_{3}$ is entirely consistent with the observation that net dividends are strictly positive along this path. 


\section{IZA Discussion Papers}

\begin{tabular}{|c|c|c|c|c|}
\hline No. & Author(s) & Title & Area & Date \\
\hline 397 & $\begin{array}{l}\text { M. Frondel } \\
\text { C. M. Schmidt }\end{array}$ & $\begin{array}{l}\text { Evaluating Environmental Programs: The } \\
\text { Perspective of Modern Evaluation Research }\end{array}$ & 6 & $11 / 01$ \\
\hline 398 & $\begin{array}{l}\text { M. Lindeboom } \\
\text { F. Portrait } \\
\text { G. J. van den Berg }\end{array}$ & $\begin{array}{l}\text { An Econometric Analysis of the Mental-Health } \\
\text { Effects of Major Events in the Life of Elderly } \\
\text { Individuals }\end{array}$ & 5 & $11 / 01$ \\
\hline 399 & $\begin{array}{l}\text { J. W. Albrecht } \\
\text { J. C. van Ours }\end{array}$ & $\begin{array}{l}\text { Using Employer Hiring Behavior to Test the } \\
\text { Educational Signaling Hypothesis }\end{array}$ & 1 & $11 / 01$ \\
\hline 400 & R. Euwals & $\begin{array}{l}\text { The Predictive Value of Subjective Labour } \\
\text { Supply Data: A Dynamic Panel Data Model with } \\
\text { Measurement Error }\end{array}$ & 5 & $11 / 01$ \\
\hline 401 & $\begin{array}{l}\text { J. Boone } \\
\text { P. Fredriksson } \\
\text { B. Holmlund } \\
\text { J. C. van Ours }\end{array}$ & $\begin{array}{l}\text { Optimal Unemployment Insurance with } \\
\text { Monitoring and Sanctions }\end{array}$ & 3 & $11 / 01$ \\
\hline 402 & $\begin{array}{l}\text { O. Ashenfelter } \\
\text { D. Card }\end{array}$ & $\begin{array}{l}\text { Did the Elimination of Mandatory Retirement } \\
\text { Affect Faculty Retirement Flows? }\end{array}$ & 5 & $11 / 01$ \\
\hline 403 & L. Ljungqvist & How Do Layoff Costs Affect Employment? & 1 & $11 / 01$ \\
\hline 404 & $\begin{array}{l}\text { H. Battu } \\
\text { C. R. Belfield } \\
\text { P. J. Sloane }\end{array}$ & Human Capital Spill-Overs Within the Workplace & 1 & $11 / 01$ \\
\hline 405 & L. Locher & Testing for the Option Value of Migration & 3 & $11 / 01$ \\
\hline 406 & $\begin{array}{l}\text { P. Garibaldi } \\
\text { E. Wasmer }\end{array}$ & $\begin{array}{l}\text { Labor Market Flows and Equilibrium Search } \\
\text { Unemployment }\end{array}$ & 1 & $11 / 01$ \\
\hline 407 & $\begin{array}{l}\text { R. Schettkat } \\
\text { L. Yocarini }\end{array}$ & $\begin{array}{l}\text { Education Driving the Rise in Dutch Female } \\
\text { Employment: Explanations for the Increase in } \\
\text { Part-time Work and Female Employment in the } \\
\text { Netherlands; Contrasted with Germany }\end{array}$ & 5 & $12 / 01$ \\
\hline 408 & $\begin{array}{l}\text { H. N. Mocan } \\
\text { E. Tekin }\end{array}$ & $\begin{array}{l}\text { Nonprofit Sector and Part-Time Work: An } \\
\text { Analysis of Employer-Employee Matched Data } \\
\text { of Child Care Workers }\end{array}$ & 1 & $12 / 01$ \\
\hline 409 & $\begin{array}{l}\text { P. Apps } \\
\text { R. Rees }\end{array}$ & Fertility, Female Labor Supply and Public Policy & 6 & $12 / 01$ \\
\hline 410 & $\begin{array}{l}\text { H. Lehmann } \\
\text { J. Wadsworth }\end{array}$ & $\begin{array}{l}\text { Wage Arrears and the Distribution of Earnings in } \\
\text { Russia }\end{array}$ & 4 & $12 / 01$ \\
\hline 411 & S. Stillman & $\begin{array}{l}\text { The Response of Consumption in Russian } \\
\text { Households to Economic Shocks }\end{array}$ & 4 & $12 / 01$ \\
\hline 412 & $\begin{array}{l}\text { M. Barbie } \\
\text { M. Hagedorn } \\
\text { A. Kaul }\end{array}$ & $\begin{array}{l}\text { Government Debt as Insurance against } \\
\text { Macroeconomic Risk }\end{array}$ & 7 & $12 / 01$ \\
\hline
\end{tabular}

An updated list of IZA Discussion Papers is available on the center's homepage www.iza.org. 